\title{
Modernization of Technical Requirements for Licensing of Advanced Non-Light Water Reactors: LMP Lessons Learned, Best Practices, and Frequently Asked Questions
}

Wayne L Moe, Amir Afzali

March 2020

The INL is a U.S. Department of Energy National Laboratory operated by Battelle Energy Alliance

Idaho National Laboratory 


\section{Modernization of Technical Requirements for Licensing of Advanced Non-Light Water Reactors: LMP Lessons Learned, Best Practices, and Frequently Asked Questions}

Wayne L Moe, Amir Afzali

March 2020

Idaho National Laboratory Idaho Falls, Idaho 83415

http://www.inl.gov

Prepared for the

U.S. Department of Energy

Under DOE Idaho Operations Office

Contract DE-AC07-05ID14517 


\section{$\triangle$ \\ Southern Company}

Modernization of Technical Requirements

for Licensing of Advanced Non-Light Water Reactors:

LMP Lessons Learned, Best Practices, and Frequently Asked Questions

Document Number

SC-29980-106 Rev 0

March 2020

Prepared for:

U.S. Department of Energy (DOE)

Office of Nuclear Energy

Under DOE Idaho Operations Office

Contract DE-AC07-05ID14517 


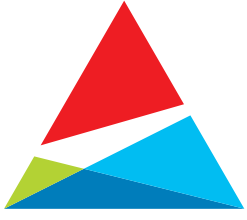 \\ Southern Company}

Modernization of Technical Requirements

for Licensing of Advanced Non-Light Water Reactors:

LMP Lessons Learned, Best Practices, and Frequently Asked Questions

Document Number

SC-29980-106 Rev 0

Issued by:

Amir Afzali, Next Generation Licensing and Policy Director Southern Company Services 


\section{Disclaimer}

This report was prepared as an account of work sponsored by an agency of the United States (U.S.) Government. Neither the U.S. Government nor any agency thereof, nor any of their employees, nor Southern Company, Inc., nor any of its employees, nor any of its subcontractors, nor any of its sponsors or co-funders, makes any warranty, expressed or implied, or assumes any legal liability or responsibility for the accuracy, completeness, or usefulness of any information, apparatus, product, or process disclosed, or represents that its use would not infringe privately owned rights. Reference herein to any specific commercial product, process, or service by trade name, trademark, manufacturer or otherwise, does not necessarily constitute or imply its endorsement, recommendation, or favoring by the U.S. Government or any agency thereof. The views and opinions of authors expressed herein do not necessarily state or reflect those of the U.S. Government or any agency thereof. 


\begin{abstract}
This report captures lessons learned, best practices, and frequently asked questions with responses gleaned from the experiences of early adopters of the LMP RIPB process. Interviews were conducted in late 2019 with five non-LWR design organizations to gather their feedback on the application of the LMP RIPB process under real production conditions.

The overall feedback from the reactor developers is that the LMP RIPB process can be successfully implemented with material benefits to the designer. As with any new processes, numerous challenges and questions were relayed by the designers. These challenges have been translated into lessons learned and best practices. Those two sections address both technical and organizational aspects of implementing the LMP RIPB process. Questions that were asked by multiple designers were turned into "frequently asked questions" and responses were provided by the LMP team.
\end{abstract}




\section{Table of Contents}

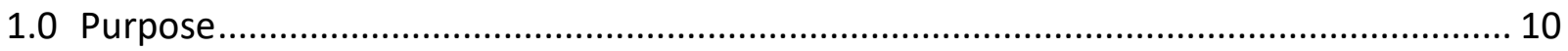

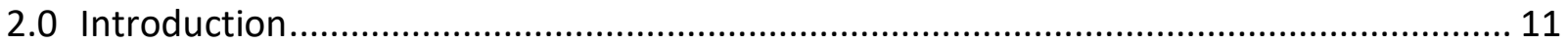

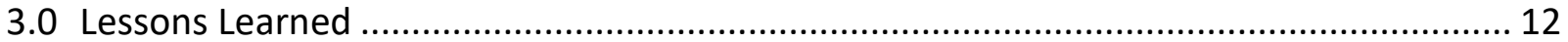

3.1 Initiating Events; Failure Modes and Effects Analysis:........................................... 12

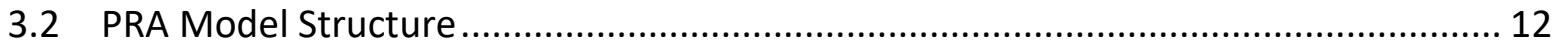

3.3 SSC Classification and Applicable Design Codes.................................................. 12

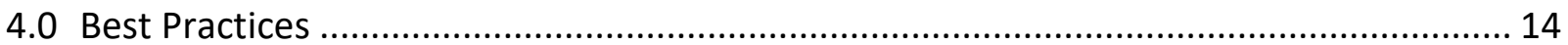

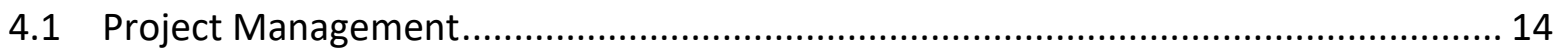

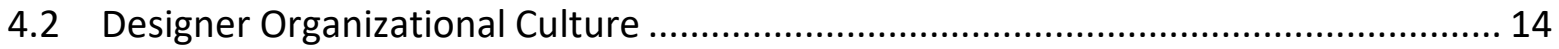

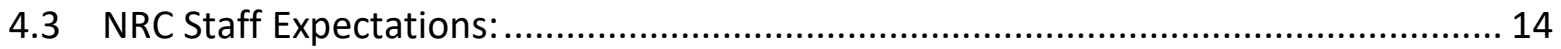

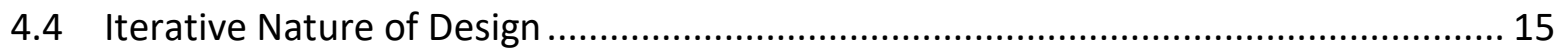

4.5 Conflicting SSC Classification Among Design Team Parties ..................................... 15

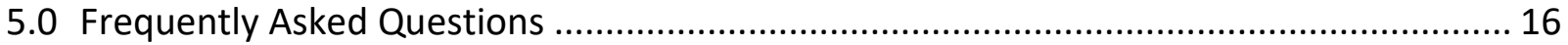

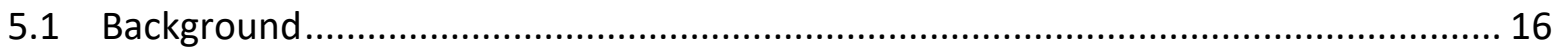

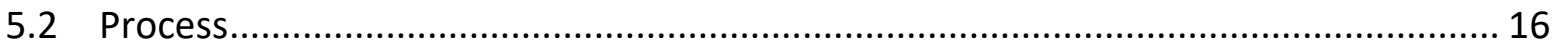

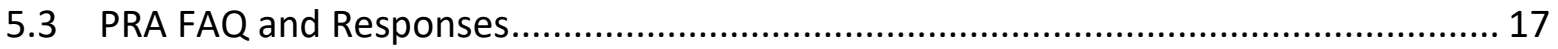

5.3.1 PRAQ1. How can the use of PRA technology to risk-inform the licensing of advanced non-LWRs be justified given the lack of operating experience with these reactors?.

5.3.2 PRAQ2. How to develop adequate PRA data for initiating events and frequencies, component failure rates, maintenance unavailability, and other PRA data needs?

5.3.3 PRAQ3. What is the role of the PRA in the SSC safety classification process, and how does safety classification influence the PRA models and data?

5.3.4 PRAQ4. What is the role of absolute and relative risk significance criteria in the LMP methodology?.

5.3.5 PRAQ5. What is the applicability of 10 CFR 50 Appendix B to PRA in the LMP methodology? .................................................................... 20

5.3.6 PRAQ6. What is the available guidance for the systematic search for initiating events for the PRA on advanced non-LWRs?.

5.3.7 PRAQ7. How does the LMP methodology identify and evaluate "cliff edge" effects?. 
5.3.8 PRAQ8. How does the structure of the PRA event tree logic impact the identification of the Required Safety Functions and the selection of the SR SSCs?

5.3.9 PRAQ9. How can the PRA standard requirements be met during the design stage when as-built and as-operated information is not available?

5.3.10 PRAQ10. What is the available guidance on how RSFs are determined, how they relate to Fundamental Safety Functions?

5.3.11 PRAQ11. What guidance is available on the PRA treatment of safety functions provided via passive means and utilizing inherent reactor features?

5.3.12 PRAQ12. How can the LMP methodology be applied using dynamic PRA methods? 26

5.3.13 PRAQ13. How does LMP address events that are not modeled in the PRA? 26

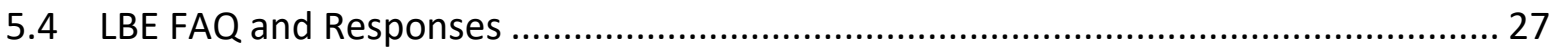

5.4.1 LBEQ1. What is the available guidance for how to develop mechanistic source terms using the PRA and supporting deterministic processes?

5.4.2 LBEQ2. How is the safety classification and special treatment of SSCs influenced by the placement of LBEs as AOOs vs. DBEs or Beyond Design Basis Events (BDBEs)?

5.4.3 LBEQ3. Is there additional information available on the selection of the F-C Target anchor points for evaluating the risk-significance of LBEs?

5.4.4 LBEQ4. What insights were obtained for using the $\mathrm{F}-\mathrm{C}$ charts from the LMP tabletop exercises and from discussions with the NRC Staff regarding DG-1353 and SECY-19-0117?

5.5 SSC Classification FAQ and Responses 31

5.5.1 SSCQ1. What guidance is available on how to select among candidates for SR SSCs and possible conflicts with ARDCs?

5.5.2 SSCQ2. What guidance is available for how to classify NSRST SSCS and how to come up with STs?

5.5.3 SSCQ3. What guidance is available for how to consider whether an SSC is classified as NSRST as necessary for adequate DID?

5.5.4 SSCQ4. What guidance is available for how to address the full scope of SSCs in a plant, including I\&C, support systems, active SSCS, passive SSCs relying on inherent features, and SSCs necessary to implement safety-significant operator actions? 
5.5.5 SSCQ5. What guidance is available for how to consider the need to protect SR SSCs against Design Basis External Hazard Levels and how to consider the requirements for NST and NSRST SSCs?

5.5.6 SSCQ6. What guidance is available to discuss how SSC classification

flows down from RSFs to major components and subcomponents to establish SRDC at the lowest level?

5.5.7 SSCQ7. What guidance is available on how to set reliability and capability targets for safety-significant SSCs?

5.5.8 SSCQ8. What is the relationship between the Maintenance Rule scope and the LMP SSC approach to assuring reliability and capability targets for NSRST and NST components?.

5.5.9 SSCQ9. IEEE standards for I\&C design only consider two safety classifications, 1E or non-1E. 1E is for safety functions or supporting systems that perform safety functions. Software $Q A$ for $1 E$ is very complex and expensive. $1 \mathrm{E} \mathrm{V \& V}$ is also complex and difficult (i.e. exploration for unintended functions and behavior). The same concept of existing industrial codes and standards having binary rules for safety-related and non-safety-related SSC, but not addressing the "middle" NSRST, is encountered often across standards development organizations. Should equipment classified by LMP as NSRST be treated as $1 \mathrm{E}$ or non-1E (or, as safety-related or non-safety-related) and why? 36

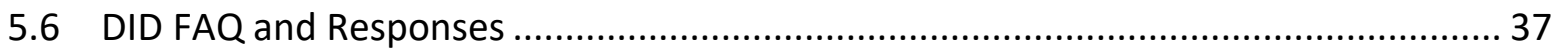

5.6.1 DIDQ1. What guidance is available on how to examine the results, limitations, uncertainties and omissions from the PRA for making IDP decisions that impact SSC safety classification and ST or deciding on practical compensatory actions?.

5.6.2 DIDQ2. What guidance is available on how to organize the IDP and update the DID baseline through design iterations?

5.6.3 DIDQ3. What is the distinction between the IDP and the IDPP, and why is it important?.

5.6.4 DIDQ4. What additional guidance is there regarding the evaluation of Plant Capability DID for low dose or no dose (e.g., "zero consequence") LBEs and the determination of NSRST SSCs?

5.7 Project Management Common FAQ and Responses

5.7.1 PMQ1. What guidance is available for how to manage the iterative process of design development, PRA development, and selection of codes and standards for SSCs? 
5.7.2 PMQ2. How does a designer know that they are completely done implementing the LMP RIPB process with a reactor design? What is the definitive "pencils down"/"finish line" event?

6.0 References....... 


\section{List of Figures and Tables}

Figure 1. Use of the F-C Target to Define Risk-Significant LBEs........................................... 20

Figure 2. Frequency-Consequence Target (Supersedes Figure 3-1 in NEI 18-04) ..................... 29

Figure 3. Use of Frequency-Consequence Target to Define Risk Significant LBEs (Supersedes

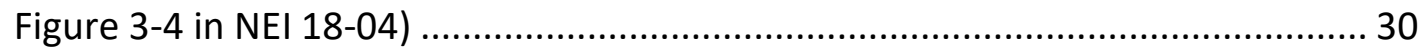

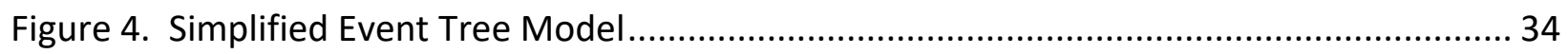

Figure 5. Traditional Design Development Process and RIBP Evaluation............................... 43

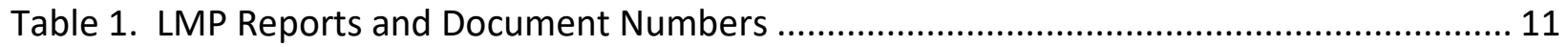

Table 2. Examples of Required Safety Functions Identified in LMP Demonstrations ................ 23 


\section{List of Abbreviations}

\begin{tabular}{|c|c|c|c|}
\hline ANS & American Nuclear Society & MHTGR & a specific modular high- \\
\hline AOO & $\begin{array}{l}\text { Anticipated Operational } \\
\text { Occurrence }\end{array}$ & & $\begin{array}{l}\text { temperature gas-cooled } \\
\text { reactor designed by General }\end{array}$ \\
\hline \multirow[t]{2}{*}{ ASME } & American Society of & & Atomics \\
\hline & Mechanical Engineers & MLD & Master Logic Diagram \\
\hline BDBE & Beyond Design Basis Event & MSRE & Molten Salt Reactor \\
\hline CFR & Code of Federal Regulations & & Experiment \\
\hline DBA & Design Basis Accident & NEI & Nuclear Energy Institute \\
\hline DBE & Design Basis Event & NGNP & Next Generation Nuclear Plant \\
\hline DBEHL & $\begin{array}{l}\text { Design Basis External Hazard } \\
\text { Level }\end{array}$ & $\begin{array}{l}\text { non-LWR } \\
\text { NRC }\end{array}$ & $\begin{array}{l}\text { non-light water reactor } \\
\text { Nuclear Regulatory }\end{array}$ \\
\hline DID & defense-in-depth & & Commission \\
\hline DOE & Department of Energy & NSRST & Non-Safety-Related with \\
\hline FAQ & frequently asked questions & & Special Treatment \\
\hline $\mathrm{F}-\mathrm{C}$ & Frequency-Consequence Target & NST & Non-Safety-Related with No \\
\hline Target & & & Special Treatment \\
\hline \multirow[t]{2}{*}{ FMEA } & Failure Modes and Effects & PDC & Principal Design Criteria \\
\hline & Analysis & PRA & probabilistic risk assessment \\
\hline HAZOP & Hazard and Operability Study & PRISM & Power Reactor Inherently Safe \\
\hline HBFT & Heat Balance Fault Tree & & Module \\
\hline IDP & $\begin{array}{l}\text { Integrated Decision-Making } \\
\text { Process }\end{array}$ & RFDC & $\begin{array}{l}\text { Required Functional Design } \\
\text { Criteria }\end{array}$ \\
\hline IDPP & $\begin{array}{l}\text { Integrated Decision-Making } \\
\text { Process Panel }\end{array}$ & RIM & $\begin{array}{l}\text { Reliability and Integrity } \\
\text { Management }\end{array}$ \\
\hline IEEE & $\begin{array}{l}\text { Institute of Electrical and } \\
\text { Electronics Engineers }\end{array}$ & RIPB & $\begin{array}{l}\text { risk-informed and } \\
\text { performance-based }\end{array}$ \\
\hline \multirow[t]{2}{*}{ KP-FHR } & Kairos Power Fluoride-Cooled & RSF & Required Safety Function \\
\hline & High Temperature Reactor & SFC & Single Failure Criterion \\
\hline LBE & Licensing Basis Event & SR & Safety-Related \\
\hline \multirow[t]{2}{*}{ LMP } & Licensing Modernization & SRDC & Safety-Related Design Criteria \\
\hline & Project & SSC & Structures, Systems, and \\
\hline \multirow[t]{2}{*}{ LWR } & light water reactor & & Components \\
\hline & & U.S. & United States \\
\hline
\end{tabular}




\subsection{PURPOSE}

Advanced (i.e., non-light-water) reactor technologies offer developers new opportunities to enhance the reliability, efficiency, and safety of nuclear power reactors through changes in fundamental design and operation. A variety of advanced design concepts are being developed that generally trend toward increased reliance on innovative, inherent, and passive safety features. Many of these features are substantially different from components now found in large light water reactors (LWRs) that dominate the commercial operating fleet. Similarly, non-light water reactor (non-LWR) suppliers are also pursuing market niches quite different from the regional baseload power generation sites typically associated with large LWR facilities.

Nuclear plant regulatory safety assessments have focused on LWRs for decades. Consequently, the United States (U.S.) regulatory framework (i.e., regulations, technical requirements, and related compliance guidance) governing nuclear plant design, construction, and operation is tailored to address large LWRs and LWR-derived concepts. This regulatory framework requires updating to be technology-inclusive (TI), with commensurate reductions in associated compliance uncertainties, if non-LWR technologies are to contribute to the domestic energy supply.

The U.S. Nuclear Regulatory Commission (NRC) recognizes that modernization of key elements of the nuclear plant regulatory framework is essential to the commercial success of advanced reactors. Many of these issues appear in the "NRC Vision and Strategy: Safely Achieving Effective and Efficient Non-Light Water Reactor Mission Readiness." "[1] Additional barriers are identified in NRC Vision and Strategy Implementation Action Plans. ${ }^{[2],[3]}$

The U.S. Department of Energy (DOE) established the industry-led Licensing Modernization Project (LMP) to update key portions of the NRC regulatory framework and allow advanced reactor deployments to move forward with increased confidence. The scope of this project, executed in conjunction with NRC and industry involvement, specifically targeted assistance to non-LWR design and licensing. 


\subsection{INTRODUCTION}

As part of the continuing LMP effort, an activity was initiated in late 2019 to collect lessons learned and feedback from the advanced reactor designers that have been implementing the LMP technology inclusive, risk-informed and performance-based (RIPB) methodology.

During November and December 2019, the LMP team sought feedback from the advanced reactor designer community on their experiences implementing the LMP RIPB process. Each of the five designers that participated in the 2018 and 2019 LMP tabletop exercises were interviewed by phone or during a site visit. Additionally, the entire advanced reactor designer community was invited to provide feedback during the December 11, 2019, meeting of the Nuclear Energy Institute (NEI) Advanced Reactor Regulatory Task Force.

As a result of this effort, updates were made to each of the four existing LMP reports and the project final report listed in Table 1. The interview process identified many lessons learned and best practices that are applicable across LMP reports and reactor technologies. Topics that were cited by multiple designers were collected into a set of "frequently asked questions."

Table 1. LMP Reports and Document Numbers

\begin{tabular}{llc}
\hline \multicolumn{1}{c}{ Report Title } & $\begin{array}{r}\text { Southern Company } \\
\text { Document Number }\end{array}$ & $\begin{array}{c}\text { DOE OSTI } \\
\text { Document } \\
\text { Number }\end{array}$ \\
\hline $\begin{array}{l}\text { Selection and Evaluation of Licensing Basis Events } \\
\text { Probabilistic Risk Assessment Approach }\end{array}$ & $\begin{array}{l}\text { SC-29980-100 Rev 1 } \\
\text { SC-29980-101 Rev 1 }\end{array}$ & TBD \\
$\begin{array}{l}\text { Safety Classification and Performance Criteria for } \\
\text { Structures, Systems, and Components }\end{array}$ & SC-29980-102 Rev 1 & TBD \\
$\begin{array}{l}\text { Risk-Informed and Performance-Based Evaluation } \\
\text { of Defense-in-Depth Adequacy }\end{array}$ & SC-29980-103 Rev 1 & TBD \\
$\begin{array}{l}\text { Final Project Report } \\
\text { LMP Lessons Learned, Best Practices, and }\end{array}$ & SC-29980-105 Rev. 1 & TBD \\
\begin{tabular}{l} 
Frequently Asked Questions \\
\hline
\end{tabular} & SC-29980-106 Rev 0 & TBD \\
\hline
\end{tabular}

These lessons learned, best practices, and frequently asked questions (with appropriate answers) are assembled into this LMP report for easy, enduring reference for future users of the LMP methodology. 


\subsection{LESSONS LEARNED}

This section focuses on specific, generally technical, lessons learned by non-LWR designers through early execution of the LMP RIPB process.

\subsection{Initiating Events; Failure Modes and Effects Analysis:}

There is an absence of common, nuclear-specific, whole plant Failure Modes and Effects Analysis (FMEA) processes and procedures for non-LWRs. Several designers have found success with the probabilistic risk assessment (PRA) team using existing LWR-focused processes and procedures to develop initiating events, then comparing those results to the expert panel FMEA for the specific advanced reactor design. The FMEA report was used to help translate/clarify common LWR events into bins of similar-to-LWR initiating events for the nonLWR as well as act as a peer review of the PRA team's assessment of how Structures, Systems, and Components (SSC) can fail.

Strong, experienced PRA practitioners are very helpful in identifying initiating events for nonLWRs. Regardless of experience and skill, designers still need a formal, systematic FMEA and/or Hazard and Operability Study (HAZOP) to have confidence in identifying a sufficiently complete suite of initiating events. For either the FMEA or HAZOP process, designers need an experienced process facilitator to maximize value of the exercise. During previous non-LWR design work, one designer found that there were events identified by one process (FMEA or HAZOP) that were not identified by the other, about $2 \%$ non-common. Section 4 , PRA Development, of the report on the Westinghouse eVinci LMP tabletop exercise ${ }^{[9]}$ describes a detailed, repeatable process for identifying initiating events that future designers may wish to review.

\subsection{PRA Model Structure}

Lumping multiple reactor plant systems together in the PRA has resulted in unexpectedly challenging SSC classification efforts. Such grouping of multiple systems is normal at preconceptual phase. In one example, at the function level, grouping manual scram and diverse control scram systems together introduced unexpected challenges for the Integrated DecisionMaking Process Panel (IDPP) in making classification decisions. The lesson for PRA analysts is that the designer needs to be able to deconstruct the PRA model so that the ability of different SSCs to mitigate an event is clearly discernable and understood.

\subsection{SSC Classification and Applicable Design Codes}

Industry culture for seven decades has been to clearly classify SSC as either Safety-Related (SR) or non-Safety-Related very early in the preliminary design stage, then apply the applicable design code (e.g., American Society of Mechanical Engineers [ASME] Boiler and Pressure Vessel Code Section III). Designers have found it challenging to apply the LMP SSC classification process culturally because of a large shift from the certainty of the older, LWRcentric prescriptive SSC classification process. Designers and project managers have expressed concern about rework resulting from detailed design (e.g., piping diameter, wall thickness, and 
materials) progressing ahead of reaching stability in RIPB SSC classifications. Suggested practices to consider regarding this concern include:

- Completing the basic functional design, preparing the appropriate PRA model, and performing the RIPB SSC classification process prior to dedicating significant man-hours to detailed design

- Allowing detailed design to progress ahead of the SSC classification under certain assumptions of future SSC classification as a recognized and documented project risk

- Having the designer begin by assuming all SSC are Non-Safety-Related with no Special Treatment (NST) and only assign a higher SSC classification with a more conservative design code when required, rather than assuming a variety of SSC classifications initially

- Using historical deterministic practices to create the conceptual design to complete initial functional allocations between systems and subsystems/components

The LMP process then tests those deterministic decisions and refines the SSC classifications and special treatments as the design matures and undergoes iterations of both design updates and application of the RIPB processes. 


\subsection{BEST PRACTICES}

This section focuses on organizational and programmatic insights gained by non-LWR designers in the early execution of the LMP RIPB process.

\subsection{Project Management}

A RIPB framework demands a tightly coupled design-analysis-licensing-PRA environment. Effective project management, particularly open and regular communication within and between organizations (groups, departments, companies/organizations, etc.), is vital to project success.

\subsection{Designer Organizational Culture}

The shift from traditional prescriptive, deterministic methods of identifying licensing basis events and design basis accidents; assigning nuclear safety classification of structures, systems, and components; and adding defense-in-depth to a methodology with extensive use of a PRA can be jarring and create uncertainty within an organization. It is vital to over-communicate not only the technical RIPB process details, but also the management expectations that use of the RIPB process is the standard.

PRA analysts will experience an increased workload with more questions on a more demanding schedule under the RIPB framework than under the traditional framework. The PRA analysts need to be prepared to respond accordingly and have supportive management that recognizes when the PRA analysts are being overwhelmed and set priorities accordingly.

\subsection{NRC Staff Expectations:}

Designers are expected to have a sufficient understanding of the operation of plant systems and radionuclide release behavior to identify and account for any "cliff edge" effects in plant performance.

The topic of defense-in-depth (DID) is considered by several designers as an area that will likely require repeated discussions with the NRC staff to both inform the staff of the safety case proposed and respond to questions such that the staff can prepare their Safety Evaluation Report. As such, careful documentation of decisions as described in Section 3 of the LMP DID report ${ }^{[40]}$ such that they can be easily retrieved is expected to save effort and man-hours during the NRC review process.

The topic of safety classification of SSC, particularly in the assignment of Non-Safety-Related with Special Treatment (NSRST) to SSC relied upon for establishing DID adequacy, is considered by several designers as an area that will likely require repeated discussions with the NRC staff to both inform the staff of the safety case proposed and respond to questions such that the staff can prepare their Safety Evaluation Report. As such, careful documentation of decisions as described by DID report Section 3.4 and SSC report Section 2.2 such that they can be easily retrieved is expected to save effort and man-hours during the NRC review process. 


\subsection{Iterative Nature of Design}

All design processes are iterative in nature, with various systems progressing and maturing at varying rates. With an RIPB process, which is likewise iterative, maintaining alignment between the PRA model and ongoing design work is key. Establishing and maintaining a robust configuration management process across all involved organizations from the start is critical. Management should establish and continuously reinforce the expected standards for use.

\subsection{Conflicting SSC Classification Among Design Team Parties}

As noted repeatedly in this report, a key management function is to ensure that robust project management and configuration control is established and maintained across all organizations involved with the reactor plant design. The areas addressed by the LMP RIPB methodology are so fundamental to the success of the design and licensing effort, deviations in execution methodology cannot be accommodated. An area that has been identified as challenging by multiple designers is that of SSC classification. The LMP RIPM method of SSC classification does not align with legacy deterministic methods, i.e., those published by the American Nuclear Society (ANS) and the Institute of Electrical and Electronics Engineers (IEEE) for light water reactor designs. Those legacy deterministic methods, however, are embedded in organizational culture, processes, and procedures. Without appropriate training on this new method, and explicit and continuing direction to apply the LMP RIPB methodology for SSC classification to all SSC, it has been observed that elements of the design organization have returned to these deterministic methodologies. Using different SSC classification methods will not produce a consistent, unified design or licensing bases. Likewise, the LMP RIPB methodology is an integrated whole, designers cannot pick and choose which parts to use or not use; both the NRC staff in DG-1353 and the ACRS in their letter report are clear that the LMP RIPB methodology is to be applied in whole within its scope. 


\subsection{FREQUENTLY ASKED QUESTIONS}

\subsection{Background}

As part of the continuing LMP effort, an activity was initiated in late 2019 to collect lessons learned and feedback from the advanced reactor designers that have been implementing the LMP technology inclusive, RIPB methodology.

During November and December 2019, the LMP team sought feedback from the advanced reactor designer community on their experiences implementing the LMP RIPB process. Each of the five designers that participated in the 2018 and 2019 LMP tabletop exercises were interviewed by phone or during a site visit. Additionally, the entire advanced reactor designer community was invited to provide feedback during the December 11, 2019, meeting of the NEI Advanced Reactor Regulatory Task Force.

The interview process identified topics that were the subject of questions by multiple designers, and thus were collected into a set of "frequently asked questions."

\subsection{Process}

An LMP team member prepared a list of questions to use as conversation starters with the advanced reactor designers based on previous verbal and written feedback to the LMP team, updated as the effort continued. Interviews were then conducted in-person or over the phone with five advanced reactor designers. Actionable feedback (questions, suggestions, lessons learned, etc.) from all designer meeting notes were then sorted into five spreadsheets corresponding to the existing four LMP reports topics (Probabilistic Risk Assessment; Licensing Basis Events; Structures, Systems, and Components Classification; Defense-in-Depth Adequacy) and a new spreadsheet for common, cross-cutting feedback. The feedback added to the spreadsheets was essentially verbatim from the meeting notes and contained designer-identifying information in context.

Once assembled, the LMP team reviewed the feedback spreadsheets. From the 79 individual line items (with much of the feedback consisting of multiple related thoughts in the same line item), the LMP team prepared 32 frequently asked questions (FAQ) which captured the underlying issues of the collected feedback, grouped according to LMP report topics. The questions prepared by the LMP team are intentionally broad in nature, covering more than one designer question. The LMP team found that while there were some unique topics raised by individual designers, the feedback received across multiple interviews was often regarding the same topics. This process allowed the LMP team to maintain the anonymity of the commenters while presenting the topics in a more technology-inclusive manner to the designer community. The LMP team then prepared responses to each of those 32 FAQ. These responses address multiple aspects of the questions' underlying issues, not just the immediate answer to the as-presented FAQ. These answers provide additional background, context, explanation, and references for the FAQ. In some instances, cross-references between related FAQs are included. This is intended to reflect that the core issues are influenced by multiple LMP sub-activities. 
Each of the existing LMP reports were updated to include a new attachment containing the list of FAQ with a pointer for the reader to this report addressing the FAQ. This report includes all the FAQ and responses.

\subsection{PRA FAQ and Responses}

\subsubsection{PRAQ1. How can the use of PRA technology to risk-inform the licensing of advanced non- LWRs be justified given the lack of operating experience with these reactors?}

To address this question, it is helpful to clarify the distinction between the PRA and statistical analysis of data. PRA is an investigation of rare events for which direct statistical data is insufficient to characterize risks using statistical methods. There is some role for statistical analyses to support a PRA, but this is performed at the level of events and components and not for estimating the overall plant risk.

The first major PRA of nuclear reactor accidents in the U.S. was the WASH-1400 Rasmussen study which was completed in 1975, before there had been a significant accumulation of large LWR service experience. ${ }^{[4]}$ The risk models and risk analyses employed in this study did not use ANY statistical analysis of LWR service experience, but rather the estimates of initiating event frequencies, component failure rates, and human error rates were based exclusively on information from non-nuclear industries and augmented using engineering judgment. The results of the Rasmussen study and associated risk insights had a major impact on the understanding of nuclear safety issues despite not having benefitted in any appreciable way from the accumulation of service experience. Such insights include the large risk significance of small break loss of coolant accidents (LOCAs), very low risk significance of large break LOCAs, importance of dependent failures including common cause failures and support system faults, and the important role of human errors.

For PRAs on advanced non-light water reactors today there are a variety of information sources and approaches to develop and quantify the PRA models as identified in response to Question PRAQ2 below.

\subsubsection{PRAQ2. How to develop adequate PRA data for initiating events and frequencies, component failure rates, maintenance unavailability, and other PRA data needs?}

The collection and analysis of PRA data for advanced non-LWRs are discussed in Section 4.1.2 in the LMP Report on PRA Development. ${ }^{[13]}$

There are four major categories of advanced non-LWRs being considered today including high temperature gas cooled reactors, sodium cooled fast reactors, molten salt reactors, and microreactors using heat pipes. There has been progress made to varying degrees to develop PRA models and supporting databases for each one of these reactor types.

In contrast with the challenges faced by Rasmussen, these advanced reactor PRAs benefit from using many components and systems that are common to LWRs and therefore benefit from the LWR service experience which has been responsible for reducing uncertainties in estimating 
most of the PRA component-level data. For components unique to each advanced reactor, there is evidence to support the estimation of failure data from research and test reactors, non-reactor facilities that have service conditions similar to those in the reactors, and engineering judgements to compare the new components to those for which service data is available.

Guidance on the development of PRA data for specific non-LWR concepts is available. Reference [8] discusses the methodology and data sources used for the PRISM sodium cooled fast reactor (SFR) PRA. In Reference [9], a PRA model and supporting data are developed to apply the predecessor methodology to LMP from the Next Generation Nuclear Plant (NGNP) program to a molten salt reactor. This work is one of the data sources used to support the development of the PRA for the Molten Salt Reactor Experiment (MSRE) LMP demonstration in Reference [7]. A PRA database developed to support the MHTGR (a specific modular hightemperature gas-cooled reactor designed by General Atomics) PRA that made use of an analysis of service experience from British gas-cooled reactors is described in Reference [8]. Reference [9] describes the LMP demonstration for the Westinghouse Micro-Reactor, which used engineering judgment to apply data from LWRs and industrial sources.

A very important aspect of developing data for any PRA, including those on advanced nonLWRs, is the treatment of uncertainty in the estimation of the data parameters on initiating event frequencies, component failure rates and maintenance unavailabilities, common cause failure parameters, and human error rates. The PRA standard requires that uncertainties be addressed in all the technical elements of the PRA, including the treatment of data. ${ }^{[10]}$ Guidance on the PRA treatment of uncertainties is available in Reference [11].

There are structured processes for developing PRA data based on expert elicitation that have been applied to estimating LOCA initiating event frequencies for LWRs for which statistical analysis of service data is insufficient because the events are so rare. ${ }^{[12]}$ Such approaches may be employed to augment the data for future non-LWR PRAs as well. The PRA standard ${ }^{[10]}$ includes requirements for the use of expert opinion in support of PRA database development and other PRA inputs.

\subsubsection{PRAQ3. What is the role of the PRA in the SSC safety classification process, and how does safety classification influence the PRA models and data?}

As discussed throughout NEI 18-04 $4^{[32]}$ and the supporting LMP reports, the application of the LMP methodology may be implemented as an iterative process. In addition, there is flexibility in how and when the process tasks in the LMP methodology are applied. It is encouraged, though not required, that the PRA be introduced at an early stage of design when it is likely that the steps in the SSC safety classification have not yet been applied or perhaps only partially applied. In the case of the MHTGR and Xe-100, the PRA was initiated at an early stage of design before the conceptual design had been completed. When the PRA was initiated in each of these cases, the PRA data was developed for SSCs assuming use of commercial grade equipment with no special treatment. Special treatment may not have any significant influence on failure rates, but it does play a role in reducing uncertainties. When this approach is used, there are larger uncertainties in the assignment of failure rate data that will ultimately be reduced when special treatment is later applied; however, which SSCs will require what level of special 
treatment may not be established during PRAs performed at an earlier stage. In the case of Xe-100 and MHTGR, uncertainties in the PRA data parameters were initially assessed to be very large to account for both the relative lack of operating experience and the lack of any special treatment controls. When the SSC safety classification steps of the LMP are applied, reliability and capability targets are set for the safety significant SSCs. These targets consider how reliable and capable the SSCs were assessed in the PRA and how much the performance may deviate without adversely impacting the risk significance of LBEs and SSCs relative to FrequencyConsequence Target (F-C Target) and cumulative risk targets. Decisions regarding special treatment and application of design codes and standards for the SSCs are intended to be made via the Integrated Decision-Making Process (IDP), which also is used for setting the reliability and capability targets. The management of uncertainty is a fundamental consideration in IDP evaluations and decisions. As a result of maturing design information, upgrades of the PRA following the implementation of the SSC classification process would be expected to reduce the level of uncertainty in the estimation of the PRA parameters for those SSCs having the greatest risk significance and may justify reduced special treatment.

\subsubsection{PRAQ4. What is the role of absolute and relative risk significance criteria in the LMP methodology?}

The LMP methodology uses absolute risk criteria to establish the risk significance of licensing basis events (LBEs) and SSCs. Absolute means that risk is evaluated against fixed targets. LBE risk significance is evaluated using the Frequency-Consequence chart shown in Figure 3-4 of NEI 18-04. This figure has been slightly revised in response to insights gained over time and for consistency with Reference [19] and is shown in Figure 1 below. (See LBEQ4 for a detailed explanation of the changes to the Y-axis legend and Risk Significant region below $5 \times 10^{-7}$.) Absolute criteria for measuring risk significance of SSCs are presented in Section 4.4.2 of NEI 18-04. Risk significant SSCs are those that provide functions that are needed to keep one or more LBEs inside the F-C Target or that make significant contributions to the LMP cumulative risk targets.

Relative risk significance criteria which are not required for LMP risk-informed decisionmaking, may be used to define the significant risk contributors to the PRA baseline risk levels to develop risk insights. They are referred to as relative criteria because they are normalized against the baseline level of risk independent of the absolute risk targets. Criteria for relative risk are given in the PRA standard, ${ }^{[10]}$ and the most common risk importance measures used for this purpose are summarized in Section 3.7.3 of the LMP report on the PRA approach. ${ }^{[13]}$ 


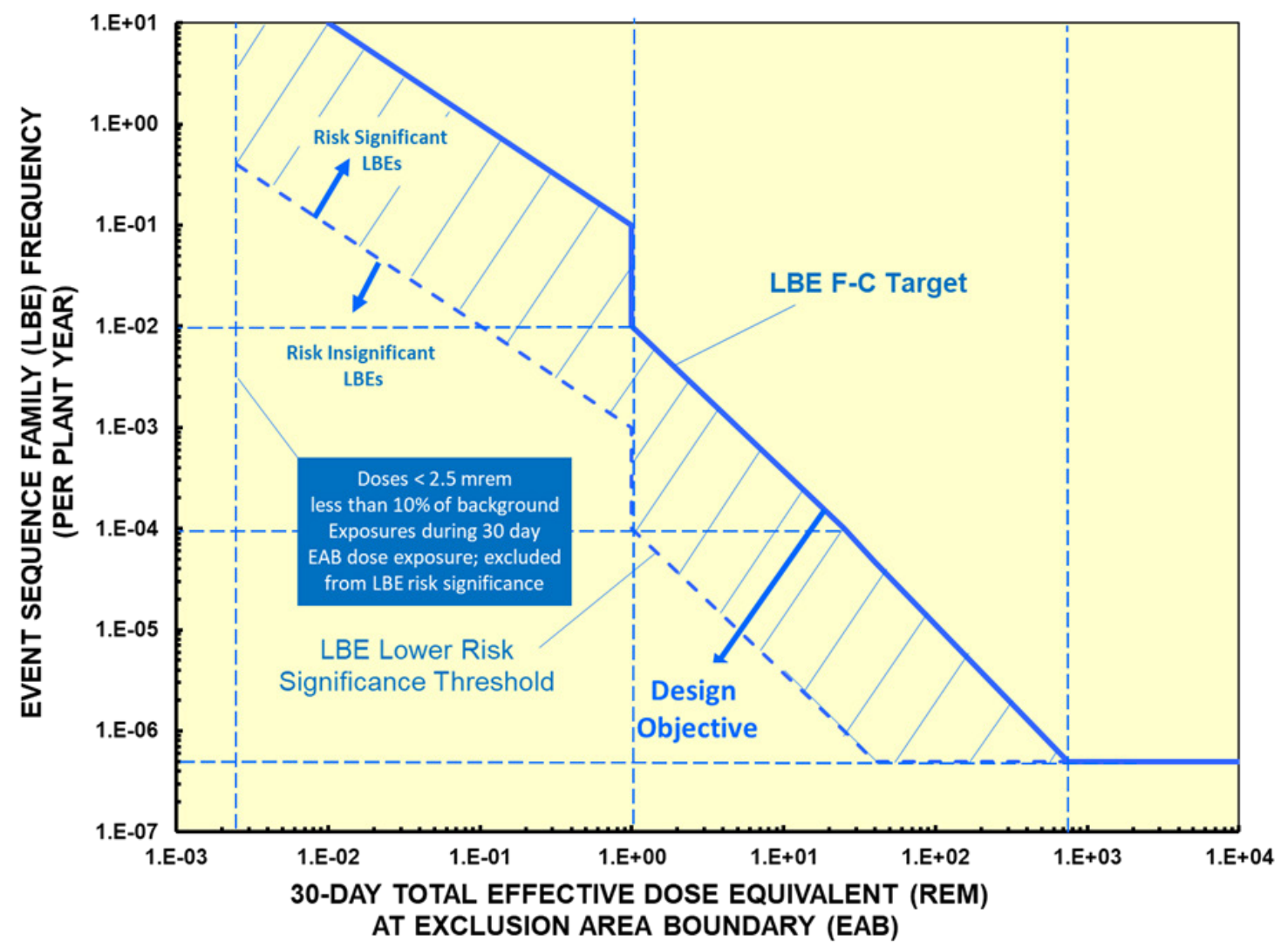

Figure 1. Use of the F-C Target to Define Risk-Significant LBEs

\subsubsection{PRAQ5. What is the applicability of 10 CFR 50 Appendix B to PRA in the LMP methodology?}

Consistent with PRA for LWRs as discussed in RG $1.200,{ }^{[20]}$ the concept of "quality assurance" as covered in 10 CFR 50 Appendix B is not applicable to performance of non-LWR PRA in support of the LMP methodology. The idea of "quality" in PRA is referred to as a "Technical Adequacy," as found in the title of Reference [20] and more recently referred to as "Technical Acceptability." The technical adequacy of a PRA is determined by satisfying the technical requirements in the PRA standard, which includes requirements for performing PRA Peer Reviews or via NRC review or audit. Although NRC has not yet endorsed the PRA standard for advanced non-LWRs, ${ }^{[10]}$ the staff is currently performing a review of that standard, and its revision to be published in 2020 and plans to publish a regulatory guide similar to RG 1.200 when this review is completed. ${ }^{[21][41]}$

\subsubsection{PRAQ6. What is the available guidance for the systematic search for initiating events for the PRA on advanced non-LWRs?}

In general, the methods for the systematic search for initiating events in PRA include: 
- Plant level FMEA where the faults are postulated at the system and system train level and the effects are evaluated on the overall plant response including an initiating event with potential adverse impacts on mitigating systems.

- Master Logic Diagram (MLD) in which a logic tree is developed in a top-down fashion to identify the causes of an adverse plant state in terms of the sources of radionuclides affected, the safety functions impacted, and the initiating events that could trigger an adverse end state.

- Heat Balance Fault Tree (HBFT) in which a logic tree is developed to identify disturbances in the plant heat balance that could initiate a plant transient and resulting initiating event.

- Process hazards analysis such as HAZOP in which deviations in plant process parameters are postulated, and their causes, effects, and corrective actions are evaluated.

- Reviews of initiating events from reactor operating experience and NRC reports, results of published PRAs.

The systematic search for initiating events for the MHTGR PRA using a form of the MLD method is described in Section 3.8.1 of the LMP report on the PRA approach. In Section 3.9.1 of that report, the selection of initiating events for PRISM is described. Additional examples of applications of these approaches may be found in many published PRAs on LWRs. The original South Texas Project PSA documents the analysis of initiating events using many of the above listed methods including MLD, HBFT, FMEA, and comparison with experience. ${ }^{[14]}$ The EPRI project on process hazard analysis to PRA transition, which was responsible for the LMP MSRE demonstration, ${ }^{[7]}$ is an excellent example of a PRA where process hazard analysis techniques such as HAZOPs were used to inform the selection of initiating events and build the knowledge base for developing a PRA model. Additional guidance for this approach is found in References [15] and [16]. More recent work to advance the development of MLDs for the systematic search of initiating events and building the PRA logic models for event sequence development may be found in References [17] and [18].

\subsubsection{PRAQ7. How does the LMP methodology identify and evaluate "cliff edge" effects?}

According to the International Atomic Energy Agency, a cliff edge effect is defined as follows: ${ }^{[22]}$

"A cliff edge effect in a nuclear power plant is an instance of severely abnormal plant behavior caused by an abrupt transition from one plant status to another following a small deviation in a plant parameter, and thus a sudden large variation in plant conditions in response to a small variation in an input."

The LMP methodology does not specifically identify whether a specific non-LWR design exhibits cliff edge effects, except that to the extent that they exist, they may be apparent in the results of the PRA which may provide risk insights for event sequences below the cutoff for Beyond Design Basis Events at $5 \times 10^{-7}$ per plant-year. The existence or lack thereof of cliff edge effects is really part of the safety characteristics of a nuclear plant and not merely a property of 
the PRA models. The PRA models are built upon the deterministic models of the plant response to events and event sequences that are used to support both the deterministic safety analyses and the PRA. There does not exist a formal definition of a cliff edge effect in the PRA standards for LWRs or non-LWRs. The method recommended in Reference [22] for identifying cliff edge effects is the performance of sensitivity studies using the deterministic models for evaluating the plant response to events.

\subsubsection{PRAQ8. How does the structure of the PRA event tree logic impact the identification of the Required Safety Functions and the selection of the SR SSCs?}

In principle, the structure of the PRA event tree logic should not impact the identification of Required Safety Functions (RSFs) and the selection of SR SSCs. First, RSFs are functions and not SSCs. RSFs are the reactor specific safety functions that enable the plant to fulfill the fundamental safety functions of retaining the radionuclides, controlling heat generation, and controlling heat removal. Reactors fulfill these functions with a combination of inherent reactor features, passive safety functions provided in part based on physical laws, and passive and active SSCs. The event tree top events in a PRA model capture those design features that have been assigned a failure probability model, but important aspects of the RSFs are reflected in the deterministic plant response models and mechanistic source term models that are used to demonstrate the success criteria and to resolve the event sequence consequences. SSCs modeled in PRA logic may be turned off and on in a binary manner to simulate their performance of the RSFs and to evaluate the SSC risk significance; it is not feasible to turn off and on in a binary manner the inherent features and some of the passive features that deliver the performance of the RSFs. The reason is that even when SSCs modeled in a binary way are postulated to fail, the resulting consequences modeled in the PRA do not fully simulate the failure to perform the RSFs.

Task 5a in Figure 3-2 in NEI 18-04 ${ }^{[32]}$ briefly describes the definition of RSFs as part of the LMP LBE evaluation methodology. Examples of RSFs were developed in Section 5.1 and 5.2 in the LMP LBE report for MHTGR and PRISM, respectively. Each of the LMP demonstration project reports on Xe-100, PRISM, MSRE, Kairos Power Fluoride-Cooled High Temperature Reactor (KP-FHR), and Westinghouse eVinci Micro-Reactor includes examples of the RSFs for each reactor, and these are summarized in Table 2. Note that the RSFs are associated with specific sources of radionuclides (Rns). 
Table 2. Examples of Required Safety Functions Identified in LMP Demonstrations

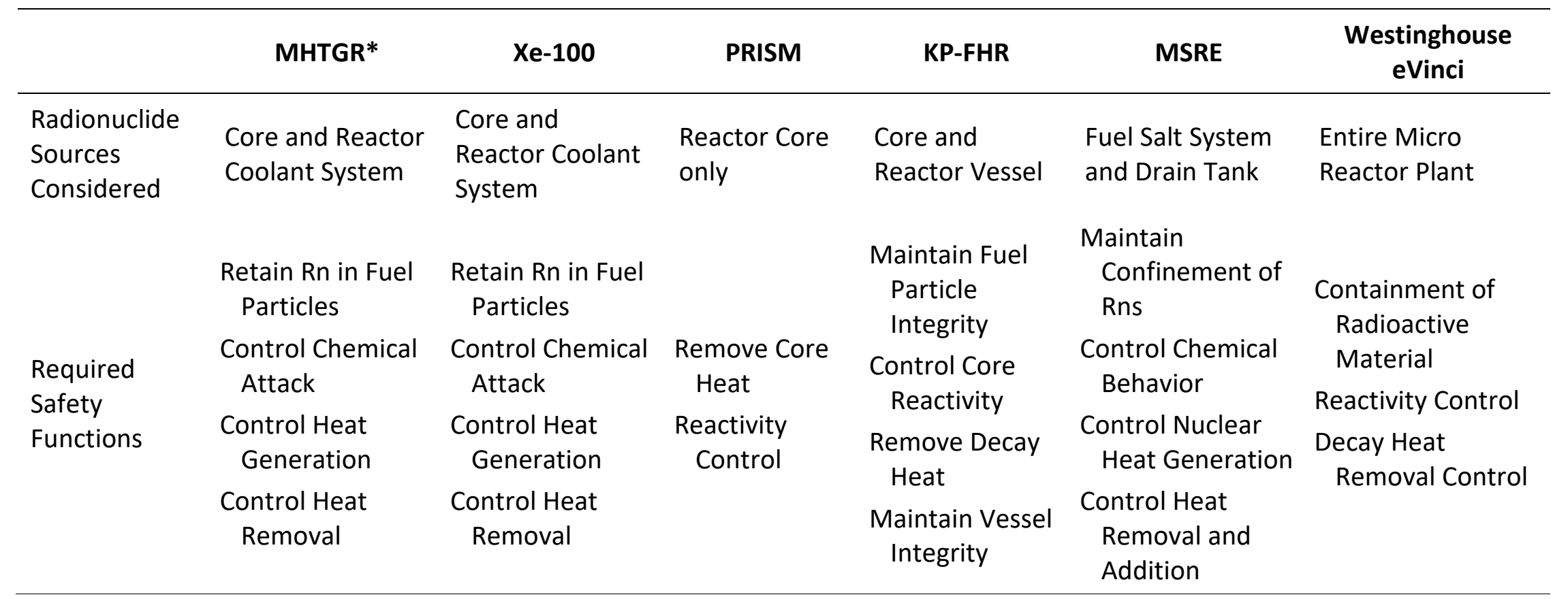

*The MHTGR exercise was conducted under a precursor of the LMP. 
One of the RSFs for the MHTGR was identified as "control core heat removal." In considering how Design Basis Events might increase in consequences if that Required Safety Function (RSF) was not fulfilled, it was determined that fuel temperatures could increase and depending on the extent to which heat removal was not controlled, the fuel temperatures could exceed ANY temperature limit including the limits where the TRISO fuel particles would fail. It was recognized that this is not a binary situation as there is no limit to how much out of control of heat removal to postulate. In reality, the core temperatures in the MHTGR Design Basis Events (DBEs) - and all LBEs - are controlled using passive and inherent design features, including core power density, core power limit, and passive heat removal phenomena, including conduction, convection, and radiation from the core to the reactor cavity. Qualitative evaluation of the safety characteristics of the reactor were sufficient to determine that this function is an RSF for this reactor.

In other LMP applications, PRA model sensitivity analyses involving turning off and on binary elements were used to help inform the selection of RSFs. While this approach is acceptable, it must be noted that such analyses are limited to seeing what the binary element is actually simulating, and it may not fully capture the entire safety function.

As a final comment on this question, if a PRA model is originally developed with the sole purpose of determining the level of risk without necessarily supporting the LMP process, it might be difficult to determine the risk significance of specific SSCs without revising the model. Hence if one were to develop the PRA model from the beginning with the purpose of supporting the LMP methodology, the construction of the model should consider the type of questions that the LMP is attempting to address, such as determining the risk significance of specific SSCs.

\subsubsection{PRAQ9. How can the PRA standard requirements be met during the design stage when as- built and as-operated information is not available?}

The PRA standard for advanced non-LWRs ${ }^{[10]}$ was developed with the specific intent of supporting PRAs being developed early in the design and in any pre-operational design, construction, and licensing stage. It is expected that the standard would be addressed prior to submittal of an application. The user may decide to partially address it an earlier stage and progressively increase its application as the design matures. When the user decides to apply the non-LWR PRA standard, there are requirements in the standard to address uncertainties, including those associated with assumptions made in lieu of actual design details which may vary over different iterations of the PRA. Guidance for uncertainty treatment is provided in Reference [11]. In addition, the PRA applications process described in the standard calls for the user to determine the appropriate scope of the PRA requirements to apply in the stage of the design when the standard is applied.

The use of the PRA standard to support early design stage PRAs is discussed in Section 4.1 of the LMP report on the PRA approach. ${ }^{[13]}$ In early 2020 , this standard is being revised to account for feedback from PRAs that have been done to pilot the Reference [10] version of the standard. In the next edition, there will be more guidance on how to apply the standard to PRAs early in the design. 
If the PRA is introduced at an early stage of design, it is expected that there will be a number of iterations involving changes to plant design, PRA upgrades and revisiting of the tasks in the LMP methodology involving LBE selection and evaluation, SSC safety classification, and selection of special treatment requirements. This is discussed in NEI 18-04 in the text that describes Figure 5-4. The impact of changes made through these iterations can be minimized if the guidance below is followed.

- In the initial performance of the PRA prior to the first attempt at safety classification, the PRA should be performed based on a conservative assumption that all modeled SSCs are commercial grade.

- As the plant design evolves and the PRA is upgraded, conservative assumptions such as assuming commercial-grade SSCs will be replaced with a more realistic assumption that will tend to reduce frequencies of LBEs as well as reduce uncertainties.

- As the DID aspects of LMP are applied, special treatments will be specified for SR and NSRST SSCs that, at a minimum, will involve the selection of performance targets for reliability and capability and specification of a performance monitoring program.

- As the above guidance is followed, the PRA results will become progressively more realistic, reducing the magnitude of uncertainties, which in turn will reduce the mean frequencies and consequences. This should greatly reduce the potential for changes later in the design process that would increase the classification and special treatments of SSCs classified as NSRST. The determination of RSFs and the selection of SR SSCs are expected to be highly stable through these iterations.

See also PMQ1 for further related reading.

\subsubsection{PRAQ10. What is the available guidance on how RSFs are determined, how they relate to Fundamental Safety Functions?}

See response to PRAQ8.

\subsubsection{PRAQ11. What guidance is available on the PRA treatment of safety functions provided via passive means and utilizing inherent reactor features?}

There are specific requirements in the PRA standard for advanced non-LWRs ${ }^{[10]}$ for addressing the impact of uncertainties in the demonstration of success criteria by SSCs that use passive means to perform safety functions. Useful guidance on how to address passive SSCs in the performance of a PRA is provided in Reference [24] based on work to modernize the PRISM PRA, which in turn made use of the methods from Reference [25]. This approach uses a quantitative analysis of uncertainties associated with the phenomena involved with the performance of the passive function to estimate the failure probability of the passive SSC. Similar approaches have been used in PRAs for design certification of advanced non-LWRs. 


\subsubsection{PRAQ12. How can the LMP methodology be applied using dynamic PRA methods?}

The LMP methodology was developed with the assumption that the PRAs would be based on the conventional event tree/fault tree methods that are reflected in the current PRA standard for both LWRs and non-LWRs. In principle, the PRA standard is supposed to define "what to do" rather than "how to do it." However, both the LWR and non-LWR standards and the supporting industry guidance on PRA peer reviews were written under the assumption that the PRA model would be based on event sequences defined in event trees and fault trees and that quantification of event sequence frequencies would be based on initiating event frequencies and basic event probabilities.

Since the inception of the PRA event tree/fault tree methodology, more advanced methods have been introduced that provide enhanced capabilities for modeling the time dependent interactions of SSC failures and event sequence progression. These are often referred to as "dynamic PRA" methods. Such methods do not use event trees, fault trees and do not represent event sequences in the form assumed in the PRA standards, but rather use simulation techniques to represent event sequences in a manner more like they occur in an actual plant. It is noted that the available methods of dynamic PRA have not been standardized in terms of scope and capability.

A significant degree of interpretation would be needed to apply the current PRA standards for both non-LWRs and LWRs to dynamic PRAs in establishing PRA technical adequacy. As explained more fully in the LMP report on evaluation of defense-in-depth adequacy, a focus of the LMP defense-in-depth evaluation is the examination of limitations and uncertainties identified from the PRA. The process for identifying these limitations and uncertainties is framed in the context of the technical requirements in ASME/ANS RA-S-1.4-2013 and the results of the peer reviews performed against this standard. Hence, when dynamic PRA methods are used, how the PRA standards and supporting peer review processes have been interpreted and applied needs to be addressed in order to establish the PRA technical adequacy and defensein-depth evaluation aspects of the LMP methodology.

\subsubsection{PRAQ13. How does LMP address events that are not modeled in the PRA?}

First, in performing the PRA against the requirements in the non-LWR PRA standard, ${ }^{[10]}$ any known or identified event that is not modeled in the PRA due to internal or external events or hazards are subject to risk significance and screening criteria in which it must be shown that inclusion of the event would not result in a risk significant event sequence or event sequence family. Then as part of the evaluation of DID adequacy, the bases for screening events out of the PRA are reviewed to identify whether some type of protective measure should be taken to address uncertainties associated with not modeled events.

See also PMQ1 and DIDQ1 for additional information. 


\subsection{LBE FAQ and Responses}

\subsubsection{LBEQ1. What is the available guidance for how to develop mechanistic source terms using the PRA and supporting deterministic processes?}

PRAs developed to support the LMP methodology, as well as deterministic safety analyses, will require the development of mechanistic source terms for event sequences involving a release of radioactive material. The term mechanistic source terms are used to identify the need to estimate the reactor design specific source terms based on the radionuclide transport mechanisms associated with that reactor, rather than a conservatively estimated source term such as was used to license existing operating reactors. Technical requirements to develop mechanistic source terms for the PRA are included in the PRA standard for advanced non-LWRs. ${ }^{[10]}$ The resulting source terms from meeting these requirements for any advanced non-LWR will be highly technology- and design-specific. The level of technology development to support mechanistic source terms is different for different reactor technologies and is most advanced for HTGRs and SFRs.

A good process for developing mechanistic source terms and the associated technology is the development of a white paper such as was done for HTGRs in the NGNP project. ${ }^{[27]}$ As part of the NGNP project, an evaluation of uncertainties in the development of mechanistic source terms for a high-temperature gas-cooled reactor design based on the South African pebble bed reactor was used to develop design specifications for the radionuclide retention capabilities of barriers including the TRISO fuel barrier, the helium pressure boundary barrier, and the reactor building barrier in Reference [27]. There has also been a lot of technology development to support the estimation of mechanistic source terms for SFRs. Reference [28] addresses how the PRA standard requirements for source terms were developed for PRISM. While these references for HTGRs and SFRs are associated with specific reactor technologies, they offer useful guidance to the work that needs to be done for other advanced reactor concepts to develop mechanistic source terms.

\subsubsection{LBEQ2. How is the safety classification and special treatment of SSCs influenced by the placement of LBEs as AOOs vs. DBEs or Beyond Design Basis Events (BDBEs)?}

The answer to this question is addressed in the text that discusses Figure 3-2 in NEI 18-04 ${ }^{[32]}$ and is expanded on in the LMP LBE report in the text that discusses Figure 1-1. ${ }^{[23]}$

To provide further clarification on this question, the following considerations are offered:

- LBEs classified as Anticipated Operational Occurrences (AOOs) have frequencies that exceed $10^{-2} /$ plant year. In nearly all cases, such LBEs involve the occurrence of a relatively high frequency initiating event with normal plant response in which SSCs that are intended to mitigate the initiating event exhibit a successful response. It would be very rare, although possible, to have an $\mathrm{AOO}$ with a combination of a high frequency initiating event and failure of an SSC that is intended to mitigate the event. In these cases, the only situation where an SSC could be classified as risk significant is if an assumed failure to perform the mitigation function would lead to a migration of the AOO outside the F-C 
Target or if the sum of LBE frequencies with that SSC failed exceeds $1 \%$ of the cumulative risk targets. It is extremely unlikely that these conditions would ever be reached, and hence it is not expected that SSCs that are involved in any AOOs will be classified as risk significant. Given this, it is also unlikely that such SSCs would be identified as performing functions deemed necessary for adequate DID, and hence AOOs should have very little if any impact on SSCs that would be classified as NSRST.

- LBEs classified as DBEs have frequencies between $10^{-4} /$ plant-year and $10^{-2} /$ plant-year. While this classification is based on mean frequencies, AOOs whose lower bound $\left(5^{\text {th }}\right.$ percentile) frequency estimate falls below $10^{-2} /$ plant-year and BDBEs whose upper bound $\left(95^{\text {th }}\right.$ percentile) estimate falls above $10^{-4} /$ plant-year are also evaluated according to the rules for DBEs. DBEs are used to inform the determination of Required Safety Functions, and they also constrain the selection of SR SSCs because such selection is limited to SSCs that are available to perform the RSFs for all the DBEs. Hence the set of DBEs (including those AOOs and BDBEs whose frequency uncertainty straddles a DBE frequency boundary) is very important input to the selection of SR SSCs.

- DBEs typically fall into two categories: One category is an LBE with a rare initiating event with a frequency between $10^{-4}$ and $10^{-2}$ /plant year with normal plant response and no additional failures of SSCs intended to mitigate the initiating event. The other category is an LBE whose frequency in the DBE region occurs as a result of a frequent initiating event and failure of one or more SSC such that the combination of the initiating event and SSC failure falls into the DBE region (failure of more than one SSC would normally be expected to move the LBE below the DBE region). DBEs are much more likely to produce risk significant SSCs than AOOs. As such, the SSCs that contribute to the DBEs are more likely to be identified as performing functions deemed necessary for adequate DID, and hence may be expected to have the potential to be classified as NSRST.

- BDBEs have frequencies between $5 \times 10^{-7} /$ plant-year and $10^{-4} /$ plant-year. While this classification is based on mean frequencies, event sequence families whose upper bound $\left(95^{\text {th }}\right.$ percentile) estimate falls above $5 \times 10^{-7} /$ plant-year are also classified as BDBEs. Such BDBEs are more likely to involve combinations of SSC failures compared with DBEs and AOOs and like DBEs are more likely to produce risk significant SSCs than AOOs. As such the SSCs that contribute to the BDBEs are more likely to be identified as performing functions deemed necessary for adequate DID, and hence may be expected to have the potential to be classified as NSRST.

\subsubsection{LBEQ3. Is there additional information available on the selection of the F-C Target anchor points for evaluating the risk-significance of LBEs?}

LMP LBE report Appendix B "Technical Basis of the LMP Frequency-Consequence Target" provides a detailed explanation of how the F-C Target was developed. 


\subsubsection{LBEQ4. What insights were obtained for using the F-C charts from the LMP tabletop} exercises and from discussions with the NRC Staff regarding DG-1353 and SECY-19-0117?

There were two insights that have resulted in changes to the F-C charts presented in NEI 18-04 that are presented below. The first insight is the need to clarify that the frequencies to be assessed and plotted on the charts for comparison to the F-C Target are for LBEs, and not for individual event sequences modeled in the PRA. LBEs are families of event sequences with a similar initiating event, plant response, and event family-driven mechanistic source term. This has led to a change on the y-axis label as shown in Figure 2 and Figure 3 below; specifically, the y-axis label text was revised from "Event Sequence Frequency" to "Event Sequence Family (LBE) Frequency." Use of event sequence families is described in NEI 18-04 Rev. 1, Section 3.2.2, Task 4. There is no change to the process for identifying and categorizing LBEs, simply a clarification of the figure $y$-axis label.

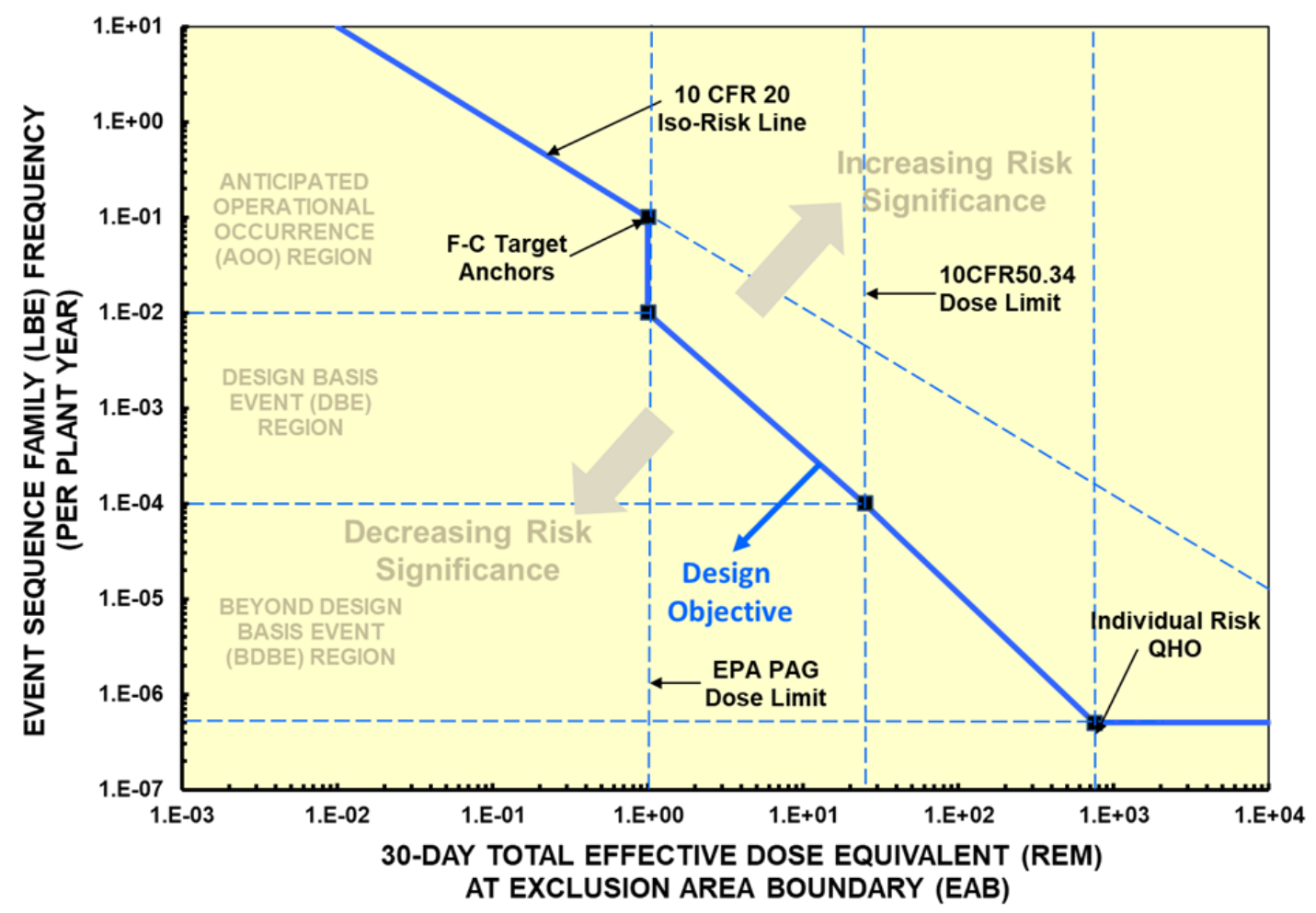

Figure 2. Frequency-Consequence Target (Supersedes Figure 3-1 in NEI 18-04) 


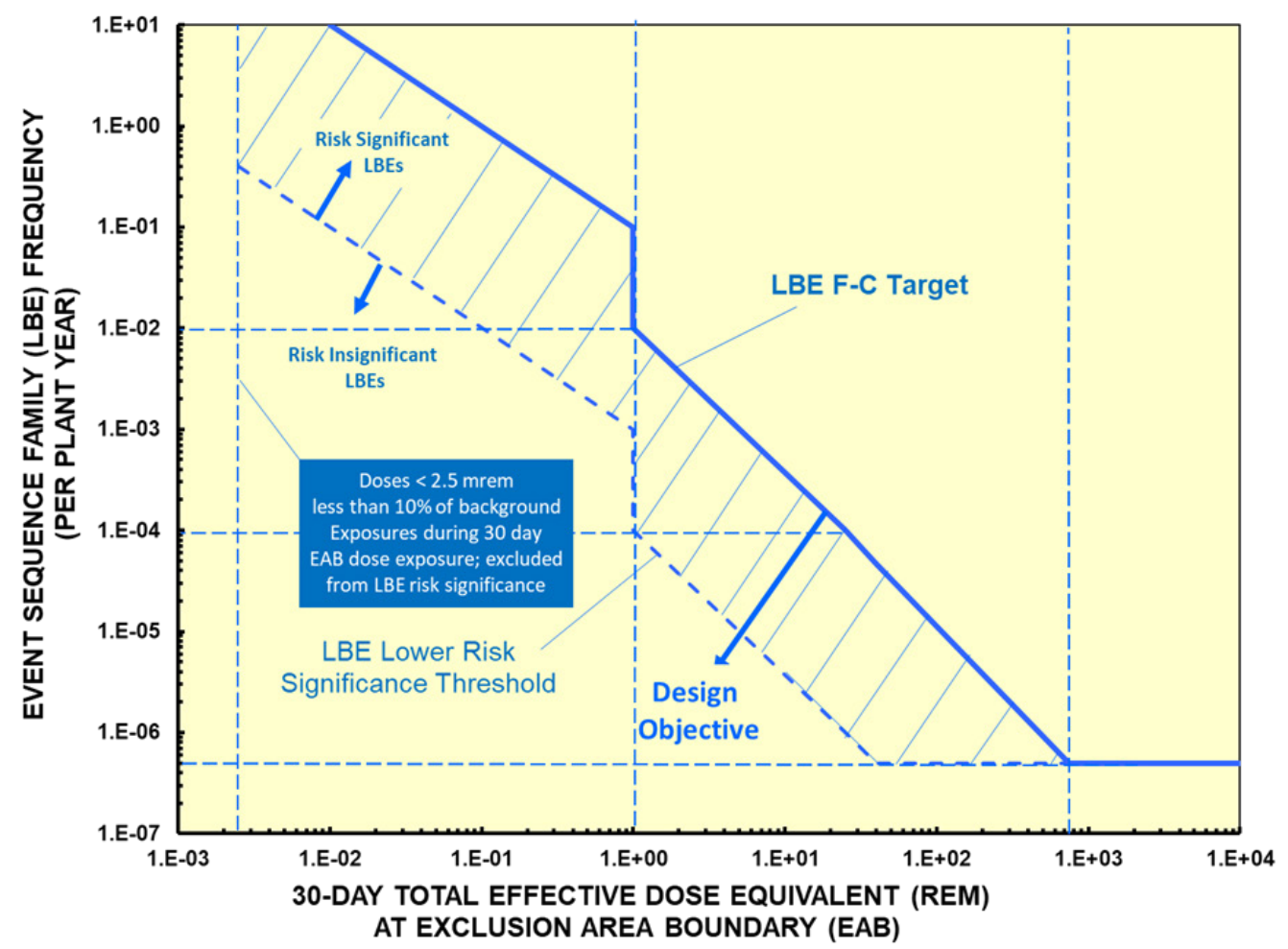

Figure 3. Use of Frequency-Consequence Target to Define Risk Significant LBEs (Supersedes Figure 3-4 in NEI 18-04)

The second insight is that it was clarified in SECY-19-0117 Figure 1 that the risk significant LBEs should not include LBE frequencies below the lower threshold for BDBEs at $5 \times 10^{-7} /$ plant year. This change is reflected in Figure 3. Specifically, the change is the elimination of the cross-hatched "Risk Significant LBEs" region below the lower threshold for BDBEs at $5 \times 10^{-7} /$ plant year.

See also "Modernization of Technical Requirements for Licensing of Advanced Non-Light Water Reactors: Selection and Evaluation of Licensing Basis Events," Rev. 1.

See also Position Paper on LMP Methodology Rules for Evaluating LBEs. 


\subsection{SSC Classification FAQ and Responses}

\subsubsection{SSCQ1. What guidance is available on how to select among candidates for SR SSCs and possible conflicts with ARDCs?}

As discussed in NEI 18-04 in the text supporting Figure 3-2, and elaborated on in the LMP LBE report $^{[23]}$ with examples for the MHTGR in Section 5.1 of that report, there are normally options available from which to select the safety-related SSCs. There must be a safety-related SSC selected to perform each Required Safety Function that is available on all the DBEs. When there are options available, which is really dependent on the design, the user may select any SSC that is available to support each RSF. Some of the considerations that may be used include the cost of the SSC and ability to demonstrate that the reliability of the SSC will meet the targets set for the SSC. All safety significant SSCs, which include SR and NSRST SSCs, will have performance targets for reliability and capability. These targets are set as part of the DID adequacy evaluation. Beyond the guidance in the LMP LBE report there is additional guidance available in the LMP demonstration reports for the MSRE, ${ }^{[7]}$ eVinci Micro-Reactor, ${ }^{[9]} \mathrm{Xe}-100$ High Temperature, Gas-Cooled, Pebble Bed Reactor, ${ }^{[2]}$ Power Reactor Inherently Safe Module (PRISM), ${ }^{[30]}$ and KP-FHR. ${ }^{[31]}$

The LMP methodology includes the definition of Required Functional Design Criteria (RFDC), and Safety-Related Design Criteria (SRDC). The RFDC are lower-tier functional criteria that are derived from the RSF. The SRDC are SSC level criteria associated with the SR SSCs. The RSF, RFDC, and SRDC are reactor technology and design specific. NEI 18-04 recommends that the RFDC and SRDC be considered as candidates for incorporation as Principal Design Criteria (PDC), which may also include selections of PDCs from the ARDCs. Hence a detailed prescription of the PDCs is not offered as part of the LMP methodology, but this topic is under consideration as part of the industry-led Technology-Inclusive Content of Application Project (TICAP).

One important deviation between the ARDCs and the LMP methodology is that ARDCs retain a Single Failure Criterion (SFC), whereas the LMP methodology uses a reliability target principle in lieu of an SFC. As noted in DG-1353, applicants following the LMP are not required to use the SFC.

\subsubsection{SSCQ2. What guidance is available for how to classify NSRST SSCs and how to come up with STs?}

SSCs that are not classified as safety-related are classified as NSRST if they meet the SSC risk significance criteria or if they perform a function that is deemed necessary for adequate DID. The risk significance criteria for SSCs are found in Section 4.2.2 of NEI 18-04. The SSCs required for DID adequacy are discussed in Section 4.3 of NEI 18-04 and this topic is discussed further in response to Question SSCQ3. 


\subsubsection{SSCQ3. What guidance is available for how to consider whether an SSC is classified as NSRST as necessary for adequate DID?}

\section{Background}

The LMP methodology developed definitions for specific terms that are similar to historical meanings but differ in the details to afford more precise language within the LMP context. See the NEI 18-04 Section 6 "Glossary of Terms" for such terms and definitions.

Safety significant SSCs are a combination of Safety-Related SSC and Non-Safety-Related with Special Treatment SSCs.

\section{Glossary}

- Safety Significant-An SSC that performs a function whose performance is necessary to achieve adequate DID or is classified as Risk-Significant (see Risk-Significant SSC).

- Risk Significant-An SSC that meets defined risk significance criteria. In the LMP framework, an SSC is regarded as risk-significant if its PRA Safety Function is: a) required to keep one or more LBEs inside the F-C Target based on mean frequencies and consequences; or b) if the total frequency LBEs that involve failure of the SSC PRA Safety Function contributes at least $1 \%$ to any of the LMP cumulative risk targets. The LMP cumulative risk targets include: (1) maintaining the frequency of exceeding $100 \mathrm{mrem}$ to less than 1/plant-year; (2) meeting the NRC Safety Goal Quantitative Health Objective for individual risk of early fatality; and (3) meeting the NRC Safety Goal Quantitative Health Objective for individual risk of latent cancer fatality.

- Safety-Related SSCs-SSCs that are credited in the fulfillment of RSFs and are capable of performing their RSFs in response to any Design Basis External Hazard Level

- Non-Safety-Related with Special Treatment SSCs-Non-safety-related SSCs that perform risk-significant functions or perform functions that are necessary for DID adequacy

\section{Response}

The NEI $18-04^{[32]}$ sections cited below contain specific guidance on this topic.

\section{Section 4.1 SSC Safety Classification Approach for Advanced Non-LWRs}

NSRST SSCs are not directly associated with RFDC but are subject to special treatment as determined by the integrated decision-making process for evaluation of DID and for meeting the reliability and capability targets set in Task 6 (see Figure 5-4).

As a part of the DID evaluation, traditional engineering judgments are made via an IDP that consider additional sources of uncertainty that are not fully resolved in the PRA. These include measures to enforce assumptions made in the PRA that may impact both frequencies and consequences or LBE margins; and measures necessary to address considerations beyond the PRA scope such as hazards intentionally not modeled in the PRA (see DIDQ1) or the number of layers of defense that provide a balance of prevention and mitigation capability for different initiating event sequences. 


\section{Section 5.6.2 Guidelines for Defining Safety-Significant SSCS}

The guidelines in Table 5-2 require that two or more independent plant design or operational features be provided to meet the plant capability requirements. As discussed in Section 4, SSCs are classified as safety-significant if they perform one or more risk-significant functions or provide a function or functions that are necessary for DID adequacy. It is appropriate that for the inherent capabilities of passive functions, degradation of the passive function is considered, as opposed to complete failure (i.e., a physical non-existence of that function). As degradation or failure of plant design or operational features is analyzed against the frequency-based guidelines in Table 5-2, the analysis should be kept in the context of risk added from these plant disruptions (i.e., certain LBEs may exceed the frequency thresholds but not carry any consequence). In the case of design changes, where risk is not increased as a result of a frequency increase, additional requirements on SSC classification or other operational solutions may not be needed. The IDP may determine whether additional requirements on SSCs (e.g., elevating classification) or other operational programs are needed to meet the Table 5-2 guidelines. The IDP may also determine that no further design requirements or operational programs are needed, or that previously identified requirements and operational programs are no longer needed to assure DID adequacy as described in Section 5.9.

Non-SR SSCs that perform a function or functions that are necessary for DID adequacy are classified as NSRST. Special treatment requirements for NSRST SSCs include the setting of performance requirements for SSC reliability, availability, and capability and any other treatments deemed necessary by the IDP for assuring DID adequacy.

\section{Section 5.7 Evaluation of LBEs Against Layers of Defense}

A central element of the RIPB evaluation of DID is a systematic review of the LBEs against the layers of defense. An important consideration in the safety classification of SSCs and in the formulation of SSC performance requirements is the understanding of the roles of SSCs modeled in the PRA in the prevention and mitigation of initiating events and event sequences across multiple layers of defense. This understanding is the basis for the formulation of the SSC capability targets for mitigation of the challenges represented in the DBE precursor LBEs as well as the reliability targets for BDBEs with risk-significant consequences to increase the confidence that additional mitigation capability is meaningful. This permits an examination of the plant capabilities evaluation in the context of the layers of defense, as delineated in Figure 5-3, to see whether additional special treatment provides meaningful assurance of public protection. The selected performance requirements would depend on the role of the supporting systems and the impact they have on achieving the RSFs when they have to act. If some of the functions are preconditions for normal operations and not required after an event starts, they may be NST or NSRST.

A generalized model for describing an event sequence in terms of the design features that support prevention and mitigation reflecting the above insights is provided in Table 5-4. This table provides an important feedback mechanism between RIPB evaluation of DID and plant capability DID. 
Figure 4 shows a simplified event tree model that was developed as part of the LMP training. In this figure, the layers of defense available to respond to an initiating event are exposed in the successive success and failure paths. The role of the SSC performance in the prevention and mitigation of each LBE is reviewed, including LBEs that may have significant or benign consequences to determine the appropriate classification. If the affected LBEs with assumed failure of the SSC is evaluated as not risk significant, the SSC may be classified as NST.

See also SSCQ8 for further guidance.

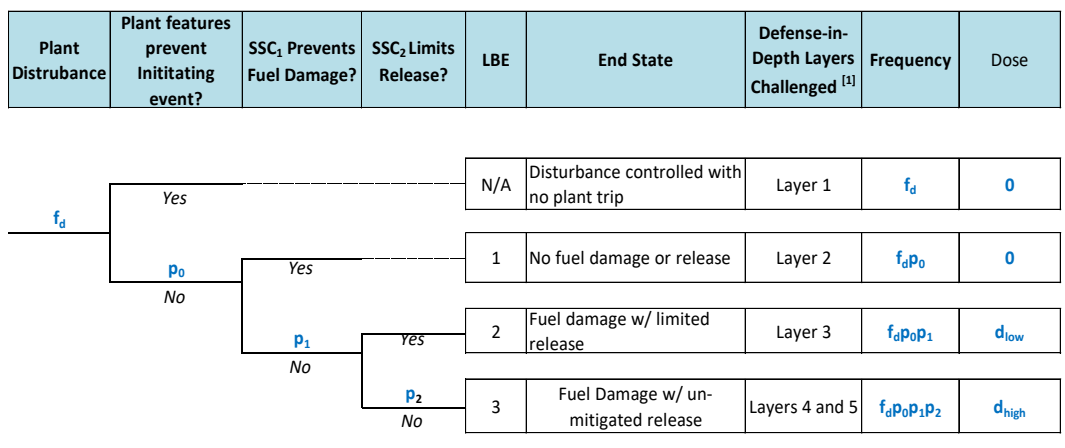

[1] See Figure 2-4 for definition of defense-in-depth layers

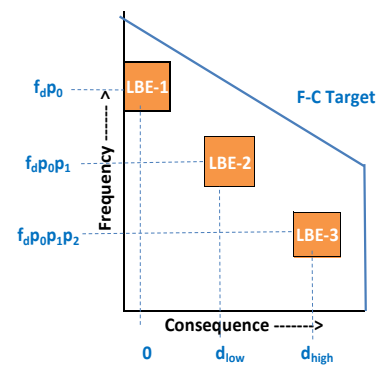

\begin{tabular}{|c|c|l|l|}
\hline SSC & LBES & \multicolumn{1}{|c|}{ Function } & SSC Performance Attribute for Special Treatment \\
\hline Plant & N/A & Prevent initiating event & Reliability of plant features preventing initiating event \\
\hline \multirow{3}{*}{ SSC $_{1}$} & 1 & Mitigate initiating event & Capability to prevent fuel damage \\
\cline { 2 - 5 } & 2 & Prevent fuel damage & Reliability of mitigation function \\
\cline { 2 - 5 } & 3 & Help prevent large release & Reliability of mitigation function \\
\hline \multirow{2}{*}{ SSC $_{2}$} & 2 & Mitigate fuel damage & Capability to limit release from fuel damage \\
\cline { 2 - 5 } & 3 & Prevent unmitigated release & Reliability of mitigation function \\
\hline
\end{tabular}

Figure 4. Simplified Event Tree Model

5.5.4 SSCQ4. What guidance is available for how to address the full scope of SSCs in a plant, including I\&C, support systems, active SSCs, passive SSCs relying on inherent features, and SSCs necessary to implement safety-significant operator actions?

Technical requirements for performing an advanced non-LWR PRA are found in the non-LWR PRA standard ${ }^{[10]}$ for all the PRA elements listed in the question. Guidance is available from the following sources in the performance of an advanced non-LWR PRA. An early PRA performed for the MHTGR is documented in Reference [33]. A more recently performed PRA that addresses the requirements in the PRA standard is summarized in Reference [34]. These PRAs are completed full scope PRAs that reflect the conceptual design stage of these reactors for a generic site. The response to PRAQ11 provides guidance for the treatment of passive SSCs that rely on inherent reactor features. The response to LBEQ1 provides a discussion on the development of mechanistic source terms that need to reflect the inherent features of the reactor.

See also SSCQ9 and PMQ1. 


\subsubsection{SSCQ5. What guidance is available for how to consider the need to protect SR SSCs against Design Basis External Hazard Levels and how to consider the requirements for NST and NSRST SSCs?}

The definition of Design Basis External Hazard Level (DBEHL) is discussed in the text for Task 6 for Figure 3-2 in NEI 18-04. The SR SSCs must be able to perform the RSFs in response to the occurrence of a design basis hazard at the DBEHL with a high degree of confidence. For a seismic event the DBEHL is the same as the design basis earthquake. This includes the prevention of any NSRST or NST SSC from failing in such a manner to prevent the SR SSCs from performing their RSFs.

DBEHLs are applicable to SR SSCs and not specifically applicable to NSRST or NST SSCs. However, when external events are incorporated into the PRA scope, additional LBEs are introduced initiated by these events. If these additional LBEs create additional risk significant SSCs or if the IDP evaluation leads to additional SSCs identified as providing functions necessary for adequate DID, this increases the population of NSRST SSCs. The reliability and capability requirements for these additional SSCs may lead to specific requirements to protect against the external hazards reflected in these SSCs.

In early 2020, additional guidance is being developed in an NRC Office of Research project for the treatment of seismic events within the LMP methodology, and a current draft is Reference [35]. The purpose of the Office of Research project is to provide the objective technical data and analyses to support future generic licensing actions (e.g., issuance of a Regulatory Guide or rulemaking) and design regarding the use of risk-informed, performancebased methods in addressing seismic hazards. Additional discussion of how external hazards are treated within the LMP process is found in LMP LBE report Appendix B.

\subsubsection{SSCQ6. What guidance is available to discuss how SSC classification flows down from RSFs to major components and subcomponents to establish SRDC at the lowest level?}

The most detailed available guidance for these aspects of the LMP methodology is found in Appendix A of the LMP report on SSC safety classification and performance requirements. ${ }^{[36]}$

\subsubsection{SSCQ7. What guidance is available on how to set reliability and capability targets for safety- significant SSCs?}

This concept was applied to implement the Reliability and Integrity Management (RIM) for the PBMR project in South Africa in the early 2000's. The RIM program is discussed in Section 3.5.1 in the LMP report on SSC safety classification and performance requirements. ${ }^{[36]}$ In the RIM program, the allocation of reliability targets starts at the plant level, which in the LMP methodology is represented by the F-C Target and the cumulative risk targets. SSC level targets are then set based on controlling the frequencies and consequences of the LBEs within those targets. The application of RIM to establish reliability and capability targets for the PBMR helium pressure boundary is discussed in Reference [37].

The RIM program is described in ASME Boiler and Pressure Vessel Code Section XI Division 2. 


\subsubsection{SSCQ8. What is the relationship between the Maintenance Rule scope and the LMP SSC} approach to assuring reliability and capability targets for NSRST and NST components?

The use of controlled maintenance programs as part of the conduct of operations are part of the Programmatic Capability described in the LMP methodology ${ }^{[32]}$ in Sections 4.4 and 5.8. There are some conceptual similarities between the 10 CFR 50.65 Maintenance Rule and the LMP approach to setting and monitoring performance of SSCs; however, they are not substitutes for one another and have significant differences in scope and implementation. Like LMP, the Maintenance Rule involves the setting of targets for reliability and maintenance unavailability for safety-related SSCs and certain non-safety-related SSCs and then for monitoring performance against these targets and taking corrective action when targets are not met. However, the LMP approach also includes setting targets for the capability of SSCs in the performance of their safety-significant functions. It is expected that the execution of the LMP process will result in fewer SSC being classified as safety-related and much clearer connection between safety functions and NSRST and NST SSCs. The application of the Maintenance Rule and other special treatments that are within the scope of the LMP approach for non-LWRs should be a topic for future discussion between applicants and the NRC. According to the LMP methodology. See also the text associated with Table 4-1 of NEI 18-04. The applicability of any category of special treatment, including the Maintenance Rule, is made in the context of its role in meeting the reliability capability requirements assigned for meeting its roles.

5.5.9 SSCQ9. IEEE standards for I\&C design only consider two safety classifications, 1E or non-1E. $1 E$ is for safety functions or supporting systems that perform safety functions. Software $Q A$ for $1 \mathrm{E}$ is very complex and expensive. $1 \mathrm{E} V \& \mathrm{~V}$ is also complex and difficult (i.e. exploration for unintended functions and behavior). The same concept of existing industrial codes and standards having binary rules for safety-related and non-safety-related SSC, but not addressing the "middle" NSRST, is encountered often across standards development organizations. Should equipment classified by LMP as NSRST be treated as 1E or non-1E (or, as safety-related or non-safety-related) and why?

Guidance for the selection of performance requirements is provided in Section 4.4 and Table 4-1 in NEI 18-04. It is emphasized in this guidance that existing codes and standards that are used in the design process were developed to support requirements for existing licensed LWR plants. These codes and standards must be applied with caution when used in conjunction with the LMP methodology. Specifically, the guidance below should be followed:

- The term "safety function" as used in this standard is associated with LWR functions associated with safety-related SSCs. Safety functions are defined differently in the glossary in NEI 18-04 and include several different types, including "Fundamental Safety Function," "PRA Safety Function," "Required Safety Function," "prevention function," and "mitigation function," all of which have different definitions and play different roles in applying the LMP methodology.

- In the LMP, the selection of codes and standards for any SR or NSRST SSC is defined on a case by case basis via the IDP based on meeting DID adequacy criteria. There is no one 
size fits all for NSRST or SR SSC. In addition, not all SR SSCs are automatically classified as Class 1E.

- As explained in NEI 18-04, 10 CFR 50 Appendix B Quality Assurance controls are only applied to SR SSC, and it could be graded to more effectively assure the SRDC performance without excess burdens.

\subsection{DID FAQ and Responses}

5.6.1 DIDQ1. What guidance is available on how to examine the results, limitations, uncertainties and omissions from the PRA for making IDP decisions that impact SSC safety classification and ST or deciding on practical compensatory actions?

\section{Background}

Historically, the evaluation of DID adequacy was performed by the NRC during the review of a license application. This frequently led to questions about the design and, not infrequently, extended discussions about changes to the design "for greater defense-in-depth." Changes at this stage of design were very disruptive and costly and the basis for these changes not well understood. This created a challenge not only for the initial plant project completion, but also for change evaluations during operations where one vague criterion is to not reduce DID. Absent a clear baseline understanding of how adequate DID was established in the licensing and how much of a change would be material to approving the change, it was difficult to evaluate the impacts on DID. The addition of a structured evaluation of DID as an integral part of design development and change management integrated with the greater use of PRA and performancebased decision making is a major feature of the LMP methodology.

\section{Response}

The evaluation of DID adequacy has been and remains a combination of hard facts and engineering judgments. The LMP guidance was created to achieve better outcomes, including:

- Move the consideration of DID much earlier in the life cycle of design development

- Provide a much-needed clarification of the attributes contributing to DID adequacy in terms that are much more discrete and actionable during the design phase without altering the NRC DID Philosophy

- Integrate the use of RIPB practices including DID into the mainstream of the design development cycles and practices

- Capitalize on the much more mature risk assessment capabilities available to more fully assess plant safety performance-based outcomes in the light of multiple sources of uncertainties

- Achieve lower burdens to plant design, construction, and operations as a result of more safety-focused solutions

As a result, DID adequacy can be built into the design, documented against the attributes evaluated as part of the Plant Capability evaluation component of DID (See NEI 18-04 Sections 
5.6 and 5.7) within the risk context defined in the LMP methodology F-C Target (described in Section 3.3.5 and shown in Figure 3-4 of NEI 18-04) and monitored throughout the plant lifetime. See also PRAQ4.

The DID IDP is designed to guide the reconciliation of competing safety and other project objectives with a bias towards conservative safety outcomes. The F-C Target and the "risksignificant" zone are conservative objectives. Uncertainties surrounding the PRA results at any given time are considered as part of the quantitative assessment of plant capability and the qualitative consideration of programmatic capability by examining DID attributes described in Section 5 of NEI 18-04. In addition to DID attributes, further guidance in Sections 5.6.1, 5.8.1, and 5.9, were developed in the form of recommended questions to be asked at some point during the IDP. Additional DID Statements of Considerations that provide further insights on DID adequacy evaluation considerations are included in NEI 18-04 Sections 5.6.2, 5.7, 5.8.2, 5.9.4 on topics ranging across:

- PRA Scope sufficiency to address the risk triplet satisfaction at maturity points

- Plant Capability Results including margins to targets

- Prevention and Mitigation across layers of defense

- Sources of Uncertainties

- Magnitude of Uncertainties

- State of Knowledge at the time of DID consideration

- Practical Compensatory Action Adequacy appropriate to risk-significance improvement desired or burdens reduced

The PRA development documentation includes the hazards screening results used to set the PRA scope (see also NEI 18-04 Section 3.3.3). Hazards identified but not modeled in the PRA are deterministically evaluated against appropriate performance-based criteria. This could be the methodology applied to small radiological sources, as well other non-radiological hazards, where the complexity and expense of developing a PRA outweigh its usefulness in establishing design objectives or evaluating non-modeled SSCs. Based on the deterministic results of non-modeled hazards, the LMP IDP is capable of guiding SSC classification and ST decisions to assure adequate design outcomes.

The management of transient assumptions and uncertainties in the design and safety case that are resolved as the design matures should be similar to the process practices that are used to manage PRA development, design development, unverified assumptions, or other open action tracking processes inherent in any design control system. Closure practices would likewise be similar for PRA or licensing or NST design action closures. (See also PMQ1 and PRAQ 9.)

The DID baseline is developed as part of the plant license application. It can be considered complete when the IDP evaluation has considered each DID attribute thoroughly. The documentation that the three sets of DID attributes in NEI 18-04 have been addressed and 
confirmed though an IDP completes the licensing baseline process. See NEI 18-04 Section 5.9.5 and also PMQ1.

Design specific questions may need to be added to the minimum list provided in NEI 18-04 due to unique features of a design. The identification of new questions is a natural consequence of considering the "Risk Triad" in DID evaluations as part of an RIPB design development.

The maintenance of a DID baseline is a necessary component of the design and licensing process and supports plant changes (design or operations) throughout the plant lifetime that may impact nuclear safety. The change management of the DID baseline begins following the submittal of the license application. (See NEI 18-04 Section 5.9.7.)

\subsubsection{DIDQ2. What guidance is available on how to organize the IDP and update the DID baseline through design iterations?}

\section{Background}

The management of the IDP is governed by the design authority and not specifically addressed in NEI 18-04. This allows implementation flexibility to the organizations accountable for completing the IDP. Also see PMQ1 and DIDQ3.

\section{Response}

The management of any design review process is governed by the responsible organization system of processes. How the IDP is integrated into existing processes is up to the design process owner. The processes guide activities throughout the design maturation cycle, including documentation supporting the various work products. The PRA at an appropriate level of detail (fit for purpose) is an integral part of modern design programs and support the execution of the design. If the RIPB process is included in the design development, then the IDP panel needs to consider the PRA output, or state why the PRA outputs or insights are incorrect or incomplete and propose compensatory actions (See NEI 18-04 section 5.3 and 5.5). At the early stage of design, the IDP cannot fully rely on the incomplete PRA. In design, the IDP process needs to have the opportunity to flag disagreements or open items and then revisit them at a future review point after the PRA team and design teams have discussed the gaps in knowledge and future planned actions. (See PMQ1)

The format for the design baseline records or process rules for developing the baseline and management of the baseline are intentionally omitted from NEI 18-04. Concepts are provided to assist in developing the DID evaluation documentation. (See NEI 18-04 Sections 5.9.5 and 5.9.6.)

\subsubsection{DIDQ3. What is the distinction between the IDP and the IDPP, and why is it important?}

\section{Background}

The NEI 18-04 List of Acronyms includes the two terms IDP and IDPP to distinguish the integrated decision-making process from the panel approach to achieving the objectives of the IDP. 
The feedback from the industry reviewers of NEI 18-04 and tabletop exercises raised questions about whether the use of panels was prescribed, preferred, efficient, or effective in all circumstances.

NEI 18-04 makes reference in Section 4.4.1 and Table 4-1 to the guidance in NEI 00-04 ${ }^{[38]}$ as one means of developing the attributes of SSC classification and its documentation and in Section 5.9.1 for the makeup and responsibilities of an IDPP. NEI 00-04 in turn, is supported by numerous guidelines or generic procedures and forms to assist licensees in conducting reviews of burden reduction under the provisions of 10 CFR 50.69, Risk-Informed Categorization and Treatment of Structures, Systems and Components for Nuclear Power Reactors. ${ }^{[39]}$

The intent of the references in NEI 18-04 was two-fold: to provide additional potential technical considerations associated with IDP activities and to provide examples for the composition of IDP reviews and IDP documentation and, if used, IDPPs.

The LMP DID report ${ }^{[40]}$ in Section 3.1 elaborates briefly on the intent more fully discussed below.

\section{Response}

The choice of integrating the IDP activities during the design development stages using the same or similar design review and approval processes applied to the myriad traditional design and safety analysis products or employing stand-alone review panels is left up to the designer in NEI 18-04. The assignment of the design authority organization changes over time as the project moves from the design-centric phases toward operation. Achieving the most efficient and effective IDP outcomes at each stage of the plant lifecycle is not prescribed or constrained by the LMP process.

Important elements of the IDP should be integrated into the routine document review and approval process for system and plant level products like System Functional Specifications, Transient and Accident Event descriptive documents (or SAR or safety case description input technical reports), licensing application section or Topical Report reviews, etc. The inclusion of cross-functional reviewers for a significant product at product development milestones is a common industry practice. Adding in safety analysis, risk analysis, and licensing members as appropriate to the subject matter being reviewed to the traditional discipline membership enables the IDP objectives to be an integral part of everyday design development. Known hot topics need to have the right people in the room, prepared in advance with safety analysis results, etc. (See also PMQ1.)

IDPPs can last a long time since they are non-routine events outside the everyday design development process and often include a wider scope of plant-level issues or multi-system portions of the plant. These are often independent of the production design decision making which is done in near real time. During the design phases, the volume of reviews and design adequacy decisions is very high and the required pace of decisions integral to the project schedule is high. Once the plant SSCs reach the "As-Designed" and "As-Built" stage, the change management process used during the plant operations phase is more practical since the volume of changes is substantially lower compared to the design development stages. Between 
the license application submittal date and the time the plant is "As-designed" the choice of whether or not to use an IDPP would likely depend on the volume of and timing impact of delayed reviews.

The NEI 00-04 process is geared to that comparatively low volume, infrequent need to execute the IDP. Plant Operations change management aligned with 10 CFR 50.59 objectives is typically done by a standing on-site panel (e.g., Plant Operations Review Committee or equivalent). Licensed plants also utilize independent plant reviews of major changes and performance trends. These are typically via a standing committee of off-site, senior management/independent expert panel (e.g., General Office Review Board or equivalent) that review safety performance and major plant modifications or operational changes.

It is important to control the IDP and IDPP, when used, so they stay on task and schedule while always allowing individuals to express their concerns, especially when it comes to safety. See also existing guidance about avoiding a chilled work environment in nuclear organizations, for example, NRC RIS 2005-18 "Guidance for Establishing and Maintaining a Safety Conscious Work Environment."

See FAQ PMQ1 for additional discussion of the integration of RIPB practices into the design starting early in the design process.

5.6.4 DIDQ4. What additional guidance is there regarding the evaluation of Plant Capability DID for low dose or no dose (e.g., "zero consequence") LBEs and the determination of NSRST SSCs?

\section{Response}

See Appendix A of the LMP DID report (Revision 1). ${ }^{[42]}$

\subsection{Project Management Common FAQ and Responses}

5.7.1 PMQ1. What guidance is available for how to manage the iterative process of design development, PRA development, and selection of codes and standards for SSCs?

\section{Background}

In the development of the LMP methodology, numerous comments were received from design organizations regarding retaining design process flexibility, timing, and accountability. The LMP methodology focuses on expectations and outcomes from using an RIPB design and licensing process.

\section{Response}

In a designer or owner System of Processes procedures for design controls, the designer retains the flexibility and accountability to establish the design controls and special treatment practices for each SSC classification category. The design processes should include procedures for conducting the IDP and, when used, an IDPP. (See also DIDQ2.) 
Well informed and effective PM, along with solid Systems Engineering practices, are needed to sequence the work and keep a thorough configuration management program in place from the beginning to track the status, unverified assumptions, and products of every SSC development step. This is a challenging, long-standing problem, i.e., documenting assumptions that require cross-disciplinary coordination. The development of the additional insights from the PRA team as an integral part of the design development process is needed to fully capitalize on the benefits of an RIPB design and licensing effort and introduces additional design process interfaces requirements that are similar to traditional design functions. During design development, there are IDPs for traditional discipline interface reconciliation. With the introduction of RIPB practices, there needs to be similar opportunities to integrate insights from the PRA team at prescribed points. Figure 5 illustrates how the traditional design development process and the RIPB evaluation of the design are related. The details of the added RIPB tasks are provided in NEI 18-04 Section 5.3. 


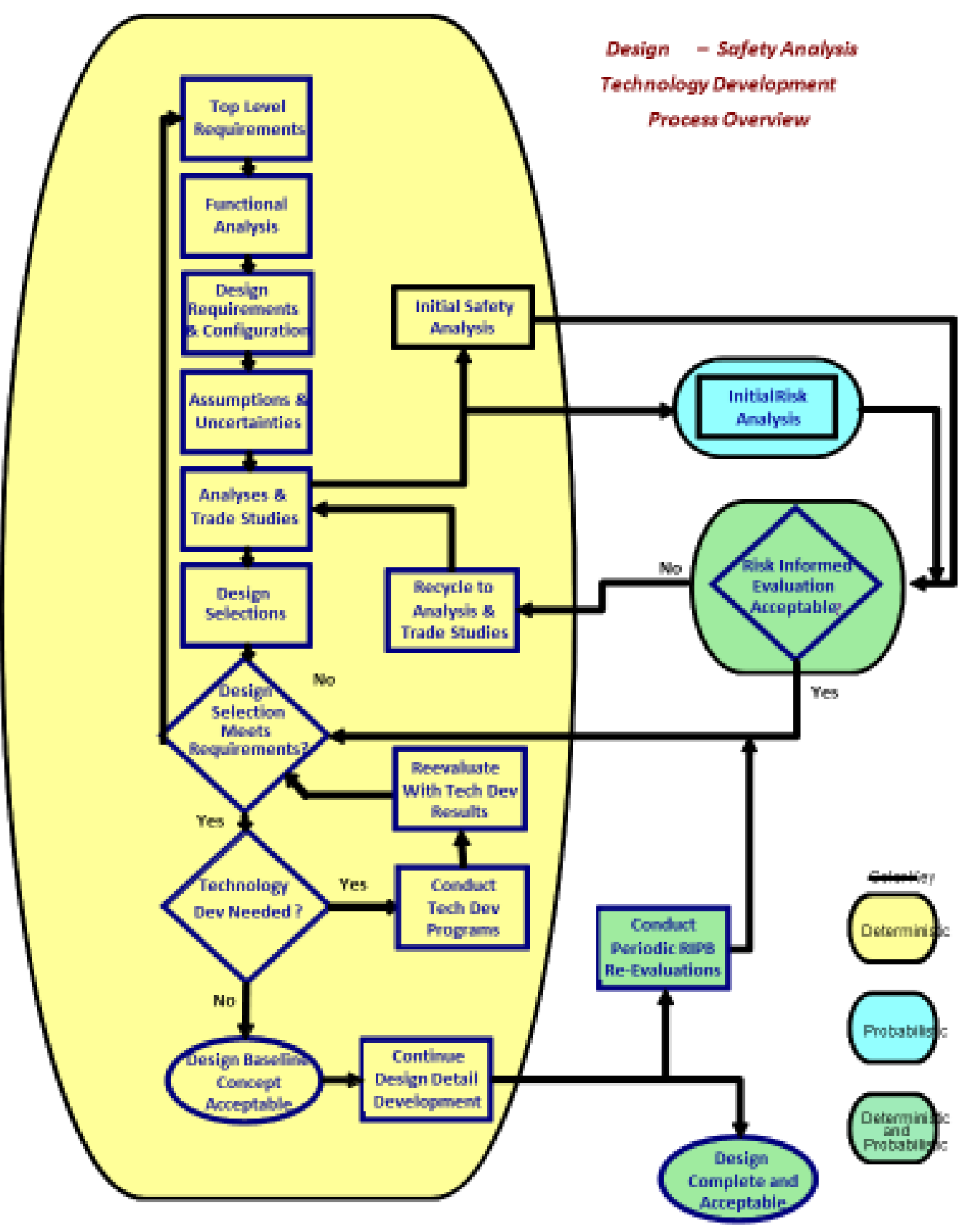

Figure 5. Traditional Design Development Process and RIBP Evaluation

Figure 5-4 of NEI 18-04 provides an integrated view of the LMP process. It includes representative iteration points for risk insights to be fed back into the design. The LMP guidance is intentionally silent on how that is done to preserve the flexibility for design organizations to select the most efficient processes and tools to execute their design work during each part of the plant lifecycle. The inclusion of cross-functional reviewers for significant products at product development milestones is a common practice. Adding in safety analysis, risk analysis, and licensing members as appropriate to the subject matter being reviewed to the traditional 
discipline membership enables the IDP objectives to be an integral part of everyday design development.

The tasks in NEI 18-04 Figure 5-4 should be integrated into the design development process and should be iteratively progressed as an integral part of the design maturity process. This allows the PRA and RIPB outcomes to be closely aligned to the state of design maturity by including PRA and licensing people in the normal design review processes. The hazards that are determined to be outside the PRA model should be deterministically evaluated by the discipline line organization responsible for those systems and components. (See also NEI 18-04 Section 3.2.3 and DIDQ1.)

Programmatic special treatment (ST) is also established over time. It evolves from the SSC classification process and is focused on only those activities that provide meaningful assurance that safety-significant SSC performance is and remains within specified design bounds. This is not an issue that has to be addressed too early in the design. However, it is important to make sure programmatic work is included in project WBS at the right time, since some performance monitoring capabilities may impact the physical design. The development of programmatic capabilities may evolve through multiple phases of maturity like design. The description of some programmatic actions, e.g., ITAAC and Technical Specifications, are included in license applications and should meet the regulatory expectations for license approval.

There are multiple drivers for ST, such as production availability, investment protection, public risk, etc. NSRST is focused solely on public risk and the ST should be focused on actions that meaningfully reduce public risk or provide additional DID assurance. Examples of ST options are included in NEI 18-04 Section 4.4.5 and in SSCQ2. ST for SSCs are initially established by the responsible design functions. The adequacy or burden of ST is also reviewed in the evaluation of DID adequacy during the IDP. See, for example, NEI 18-04 Section 5.3 Tasks 1, 13, and 16 and Table 5-7.

IDPPs can last a long time since they are non-routine events outside the everyday design development process. Important elements of the IDP should be integrated into the routine document review and approval process for system and plant level products like System Functional Specifications, Transient and Accident Event descriptive documents (or SAR or safety case description input technical reports), licensing application section or Topical Report reviews, etc. (See also DIDQ 3.)

\section{Timing}

The timing of development of RIPB insights and incorporation into the design is a designer process prerogative. Not all of the tasks in the LMP methodology need be done serially or even completely early in the design process. The objective is to complete each task as the design matures rather than being a disruptive inclusion when the design is more mature. For example, when writing functional descriptions and system specifications, the SSC classification does not matter much in early design phase. Within the PRA model, the SSC classification does not really matter to its development or outputs. What does matter is the design solution driven by the SSC classification process and the safety significance of the SSC functions. The resulting SSC classification, through design rules and objectives, drives considerations of redundancy, 
diversity, etc. at the system level, which results in improved risk profiles. It should be noted that other design objectives also drive system design. Plant output reliability and availability, provisions for on-line maintenance and testing, etc. may lead to redundancy and diversity independent of nuclear risk objectives. These capabilities also often add to the plant robustness for nuclear safety as well. The addition of these features in the conceptual plant configuration enable earlier PRA development as well.

Once the design work progresses, it gets a lot more expensive and causes more rework if the SSC classification changes, largely due to differences in applicable industry codes (e.g., ASME Boiler and Pressure Vessel Code Section III vs. ANSI B31.1 piping design). The selection of different codes has a material impact on the plant cost, so the early identification, at least for the major SR components, is an important opportunity.

The later the PRA work starts, the more challenging for the PRA team to catch up with the design and potentially more disruptive to the design team when risk insights lead to design changes. Design products such as System Functional specs and Flow Diagrams, Functional Allocations to Systems and HAZOPS begin in pre-conceptual design work. This is an early body of knowledge that the PRA analyst needs to begin the PRA model development and basic Event Tree development. The PRA should be substantially mature when the functional design products impacting safety have completed their preliminary design phase.

For early design stages, the IDP can provide feedback in areas that the PRA has not addressed yet. Since the PRA may be in its formative stages, fidelity of the model may be low, plant operating states or transient conditions are not known precisely, etc. However, inclusion of safety and risk analysts in early design trade studies can still provide qualitative insights or very simplified quantitative risk insights that help shape the design. For example, one of the simplified quantitative insights that have proven useful in the early pre-conceptual stage is the relative reliability of different design options that are being considered. Using standard industry data, simple system models, or comparative analysis can make a significant impact on the speed and confidence the early system design efforts.

The development of SSC classification is arduous. It takes some design detail to build a preliminary PRA; the PRA then informs the LBE identification, which informs SSC classification, etc. (See generally, NEI 18-04.) As the conceptual design matures, SSCs are added or deleted, SSC classifications change as functional allocations change and as PRA results become available or are updated. This is a continuously evolving product line that matures with and helps mature the design.

After the early SSC classification decisions are initially deterministically made, revisiting those decisions should be a much more clearly defined activity as the design maturity increases. The project plan to make a decision up front should be supplemented with how often the PRA will be updated and SSC classification decisions re-visited. NEI 18-04 is best implemented when the basic tasks are integrated into the schedule similar to traditional discipline products to be successful. 
The IDP has the authority to recommend a design change to the design team. This is because the IDP includes more senior, cross-disciplinary participants with the accountability and authority for the specific decisions impacting the project. However, as a review process, it does not have the authority to direct changes. That authority rests with line organizations. For example, in an early design, if the design had two good systems for heat removal, but neither on their own were sufficient to reach the F-C Target, both could be classified as safety-related or the IDP could recommend to designers to make one more reliable such that one, and only one, could be safetyrelated. Selecting one or a combination of systems is a designer's choice; to lower plant costs, preferably only one is selected. Also, design changes are one option to consider. Programmatic changes or a combination of design and programmatic changes may be the most pragmatic compensatory actions. This IDP is an effective way to engage all the technical stakeholders on design decisions at any point in the design process and use the RIPB insights to make timely changes to the design. (See PMQ1.)

The timing of completion of the LMP process is discussed in DIDQ1. Thus, designers typically make initial SSC classification deterministically. When PRA insights are available, the conceptual SSC classifications can be validated using RIPB insights. The SSC classification process must include steps to reconcile conflicting or incomplete information in the process of completing SSC classification and ST. The DID IDP is designed to guide reconciliation of competing safety and other project objectives with a bias towards conservative safety outcomes. The F-C Target and the "risk-significant" zone are conservative objectives. LMP describes the considerations within Plant Capability, Programmatic Capability, and DID evaluations and the role of costs and benefits in reaching integrated decisions.

\section{IDP Membership and Training}

Introductory training in the LMP process is essential for in-house staff and consultants involved in safety design analysis, licensing and safety system functional design, or independent safety review activities. The available industry guidance for implementation of 10 CFR 50.69 for large LWRs is a good starting point for non-LWR designers to consider in developing their IDP.

For planning purposes, it is important to build preparation time for IDP participants into the project schedule. Known hot topics need to have the right people in the room, trained and prepared in advance with safety analysis results, etc. See also DIDQ2 and DIDQ3 for further information.

\section{Burden}

Some developers perceive the DID adequacy evaluation approach may impose unnecessary requirements or burdens or be complex to implement. Any new design will be licensed, in part, on the satisfaction of the long-standing DID philosophy. It will also require a fit for purpose PRA as part of the analysis of safety performance. The LMP methodology for DID adequacy evaluation is premised on the following points:

- The existing NRC Defense in Depth Philosophy will continue, unchanged. The LMP methodology provides a structured means to evaluate DID adequacy during the design 
development and support licensing by having a more rigorous and objective framework for determining DID sufficiency.

- The LMP approach is technology-inclusive and, as such, is useful to all advanced reactor types and sizes.

- The LMP methodology is optional as a means to define a safety-focused safety design and licensing basis for a new design. The developer retains the flexibility to establish the safety case using a different approach.

- The DID adequacy evaluation is both risk-informed and performance-based.

- The DID adequacy evaluation is built on the $50+$ year legacy of the DID philosophy and the 30+ year development of RIPB design and licensing practice evolution. The process reflects inputs and reviews from a broad set of developers, owners, and current and former regulators.

- The DID process focuses on enabling a structured evaluation of DID adequacy during design development stages so DID is "built in" long before the NRC licensing review considers DID adequacy.

- The DID adequacy evaluation considers the insights from HAZOPS, PRA, margins in plant performance to risk targets, the available layers of defense, the magnitudes and sources of identified risk-significant uncertainties, overdependence on any single feature, and the residual risks from events included and not included in the PRA.

- The DID IDP allows a significant amount of flexibility to the developers in deciding when and how to satisfy the DID attributes using the available RIPB and deterministic information at any design maturity level.

- The initial experience with a variety of advanced reactor developers who have voluntarily engaged the LMP process has been positive, demonstrating that the overall process is sound, reasonable, and can deliver the intended outcomes.

- The feedback to date has not identified any necessary changes in the process description in NEI 18-04.

\subsubsection{PMQ2. How does a designer know that they are completely done implementing the LMP RIPB process with a reactor design? What is the definitive "pencils down"/"finish line" event?}

\section{Response}

The LMP RIPB process in a reactor design program continues down the same timeline as the underpinning design and safety analysis. It is, in effect, a living process that remains a part of the design bases and licensing bases through the operating lifetime of the plant.

As such, when a design feature changes, a change control process is employed to verify the completeness of the design change, the impact on the safety case and licensing case, and other programs associated with the safe construction and operation of the facility. 
The change control process changes depending on the state of maturity of the design and state of the licensing process for the plant. The design phases are typically characterized as preconceptual design, conceptual design, preliminary design, detailed design ("as-designed"), construction design ("as-built"). Similarly, the licensing process phases are broadly preapplication, application, licensed (or certified). Other terminology comparable to these phases may be used in individual companies and are acceptable as part of the management system of processes used to implement the total work of the company.

Each of these design process stages is controlled by the design authority and integrated with the licensee regulatory control process to sustain a common foundation for safety and licensing completeness and correctness. The initial milestone for completing the LMP process should be aligned with the completion of the DID baseline in the initial license application. Closure of unverified assumptions, deviations during manufacturing and construction, and observed plant performance deviations during startup and testing should consider the impacts on the DID baseline established in the license application or subsequent plant license. This will include the timing of PRA updates that identify safety-significant changes to the licensed safety case. Programs used to satisfy 10 CFR 50.59 evaluation criteria are representative of the continuing uses of LMP methods throughout the plant life.

See also the following questions:

- PMQ1 for design control process integration and maturation with LMP methodology.

- DIDQ1 for DID baseline establishment.

- DIDQ2 for DID baseline updating. 


\subsection{REFERENCES}

[1] U.S. Nuclear Regulatory Commission, "NRC Vision and Strategy: Safely Achieving Effective and Efficient Non-Light Water Reactor Mission Readiness," ML16356A670, December 2016.

[2] U.S. Nuclear Regulatory Commission, "NRC Non-Light Water Reactor Near-Term Implementation Action Plans," ML17165A069, July 2017.

[3] U.S. Nuclear Regulatory Commission, "NRC Non-Light Water Reactor Mid-Term and Long-Term Implementation Action Plans," ML17164A173, July 2017.

[4] U.S. Nuclear Regulatory Commission, "Reactor Safety Study, An Assessment of Accident Risks in U.S. Commercial Nuclear Power Plants," WASH-1400, 1975.

[5] D. Grabaskas, et al., "A Methodology for the Development of a Reliability Database for an Advanced Reactor Probabilistic Risk Assessment," Proceedings of the $24^{\text {th }}$

International Conference on Nuclear Engineering, ICONE24, Charlotte, North Carolina June 26-30, 2016.

[6] Pyron, D.A., "Safety Analysis for the Licensing of Molten Salt Reactors," Paul Scherrer Institute, 2016.

[7] Vanderbilt University, "Molten Salt Reactor Experiment (MSRE) Case Study Using Risk-Informed, Performance-Based Technical Guidance to Inform Future Licensing for Advanced Non-Light Water Reactors," September 4, 2019.

[8] U.S. Department of Energy, "Probabilistic Risk Assessment for the Standard Modular High Temperature Gas-Cooled Reactor,” DOE-HTGR-86-011, Revision 5, April 1988.

[9] A. Maioli, et al, "Westinghouse eVinci ${ }^{\mathrm{TM}}$ Micro-Reactor Licensing Modernization Project Demonstration," August 12, 2019.

[10] ASME/ANS, "PRA Standard for Advanced Non-LWR Nuclear Power Plants," ASME/ANS RA-S-1.4-2013, December 2013.

[11] U.S. Nuclear Regulatory Commission, "Guidance on the Treatment of Uncertainties Associated with PRAs in Risk-Informed Decision Making," NUREG-1855, March 2009.

[12] U.S. Nuclear Regulatory Commission, "Estimating Loss-of-Coolant Accident (LOCA) Frequencies Through the Elicitation Process,"NUREG-1829, April 2008.

[13] Southern Company, "Modernization of Technical Requirements for Licensing of Advanced Non-Light Water Reactors: Probabilistic Risk Assessment Approach," Document Number SC-29980-101 Rev 0, August 2019.

[14] Pickard, Lowe and Garrick, Inc., "South Texas Project Probabilistic Safety Assessment," PLG-0675, May 1989.

[15] Center for Chemical Process Safety, "Guidelines for Initiating Events and Independent Protection Layers in Layer of Protection Analysis," New York, NY, American Institute of Chemical Engineers, 2015. 
[16] Electric Power Research Institute, "Program on Technology Innovation: Early Integration of Safety Assessment into Advanced Reactor Design, Preliminary Body of Knowledge and Methodology,” EPRI Report 3002011801, 2018.

[17] Bechtel River Protection Project, "Low-Activity Waste Plant Nuclear Safety Model Rev 0,” 24590-LAW-RPT-NS-15-003, August 16, 2016.

[18] B. Chisholm, et al., "A Systematic Approach to Identify Initiating Events and Building a PRA Model Demonstrated on the Molten Salt Reactor Experiment," to be published in Progress in Nuclear Energy in 2020.

[19] U.S. Nuclear Regulatory Commission, "Technology-Inclusive, Risk-Informed, And Performance-Based Methodology to Inform the Licensing Basis and Content of Applications for Licenses, Certifications, And Approvals for Non-Light-Water Reactors," SECY 19-0117, December 2, 2019.

[20] U.S. Nuclear Regulatory Commission, "An Approach for Determining the Technical Adequacy of Probabilistic Risk Assessment Results for Risk-Informed Activities." Washington, DC: Regulatory Guide 1.200, Rev. 2, 2009.

[21] U.S. Nuclear Regulatory Commission, "Review and Potential Endorsement of ASME/ANS RA-S-1.4 "PRA Standard for Advanced Non-LWR Nuclear Power Plants," Presentation to U.S. NRC Advisory Committee on Reactor Safeguards, October 2, 2019.

[22] International Atomic Energy Agency, "Deterministic Safety Analysis for Nuclear Power Plants," Specific Safety Guide SSG-2, 2009.

[23] Southern Company, "Modernization of Technical Requirements for Licensing of Advanced Non-Light Water Reactors: Selection and Evaluation of Licensing Basis Events," Document Number SC-29980-100 Rev 0, August 2019.

[24] A. J. Brunett, "A Methodology for The Integration of Passive System Reliability with Success Criteria in A Probabilistic Framework for Advanced Reactors," Proceedings of the 2016 24th International Conference on Nuclear Engineering, ICONE24, Charlotte, North Carolina, June 26-30, 2016.

[25] European Commission, "RMPS Project: Reliability Methods for Passive Systems, Final Report," $5^{\text {th }}$ EURATOM Framework Programme, 1998-2002.

[26] Idaho National Laboratory, "Next Generation Nuclear Plant Mechanistic Source Terms White Paper," INL/EXT-10-17997, ADAMS Accession No. ML103050268, July 2010.

[27] D. Naidoo, et al., "Next Generation Nuclear Plant: Plant Level Assessments Leading to Fission Product Retention Allocations," NGNP-PLD-GEN-RPT-N-00007, October 2009.

[28] D. Grabaskas, et al., "A Methodology for The Integration of a Mechanistic Source Term Analysis in A Probabilistic Framework for Advanced Reactors," Proceedings of the $24^{\text {th }}$ International Conference on Nuclear Engineering, ICONE24, Charlotte, North Carolina, June 26-30, 2016.

[29] B. Waites et al., "High Temperature, Gas-Cooled Pebble Bed Reactor Licensing Modernization Project Demonstration," Document Number SC-29980-200 Rev 0, August 2018. 
[30] T. Hicks, et al., "PRISM Sodium Fast Reactor Licensing Modernization Project Demonstration," Document Number SC-29980-201, December 2018.

[31] M. Denman, et al., "Fluoride-Cooled High Temperature Reactor Licensing Modernization Project Demonstration," Document Number SC-29980-201, December 2018.

[32] Nuclear Energy Institute, NEI 18-04, "Risk-Informed Performance-Based Technology Inclusive Guidance for Advanced Reactor Licensing Basis Development," Rev 0, DOI:10.2172/1557649, April 1, 2019.

[33] U.S. Department of Energy, "Probabilistic Risk Assessment for the Standard Modular High Temperature Gas-Cooled Reactor,” DOE-HTGR-86-011, Revision 5, April 1988.

[34] D. Henneke, et al. "Development/Modernization of an Advanced Non-Light Water Reactor Probabilistic Risk Assessment,” DOEGEHH08325, March 2017.

[35] N. Choksie, et al., "A Proposed Alternative Risk-Informed and Performance-Based Regulatory Framework for Seismic Hazards at NRC Regulated Facilities,” Draft Report January 2020.

[36] Southern Company, "Modernization of Technical Requirements for Licensing of Advanced Non-Light Water Reactors: Safety Classification and Performance Criteria for Structures, Systems and Components," Revision 0, August 2019.

[37] K.N. Fleming, et al., "Reliability and Integrity Management Program for PBMR Helium Pressure Boundary Components," Proceedings of the $4^{\text {th }}$ International Topical Meeting on High Temperature Reactor Technology, Washington, DC, September 28October 1, 2008.

[38] Nuclear Energy Institute, NEI-00-04, 10 CFR 50.69 "SSC Categorization Guideline," July 2005.

[39] 10 CFR 50.69, "Risk-Informed Categorization and Treatment of Structures, Systems, and Components for Nuclear Power Reactors," December 2015.

[40] Southern Company, "Modernization of Technical Requirements for Licensing of Advanced Non-Light Water Reactors, Risk-Informed and Performance-Based Evaluation of Defense-in-Depth Adequacy,” Revision 0, August 2019.

[41] Letter from Louis Lund, NRC Standards Executive, U.S. Nuclear Regulatory Commission to C. Rick Grantom, Co-Chair and Bob Budnitz Co-Chair, ASME/ANS Joint Committee on Nuclear Risk Management, "NRC Plan for Endorsement of ASME/ANS Advanced non-LWR PRA Standard," ADAMS Accession Number 20045G141, March 13, 2013.

[42] Southern Company, "Modernization of Technical Requirements for Licensing of Advanced Non Light Water Reactors: Risk Informed and Performance Based Evaluation of Defense in Depth Adequacy," SC 29980103 Rev. 1, March 2020. 